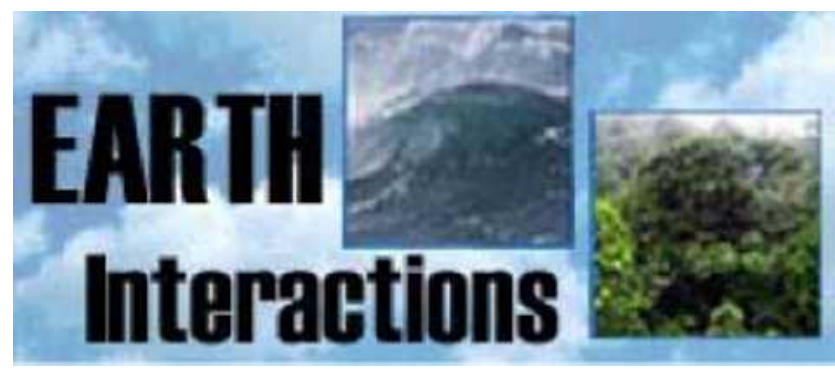

Paper 9-005; 11,883 words, 9 Figures, 0 Animations, 1 Table. http://EarthInteractions.org

\title{
Investigation of Soil Erosion from Bare Steep Slopes of the Humid Tropic Philippines
}

\section{A. L. Presbitero}

Department of Agricultural Engineering and Applied Mathematics, Visayas State College of Agriculture (ViSCA), Baybay, Leyte, Philippines

\section{W. Rose* and B. Yu}

Faculty of Environmental Sciences, Griffith University, Nathan, Queensland, Australia

\section{A. A. Ciesiolka}

Queensland Department of Natural Resources, Mines and Energy, Toowoomba, Queensland, Australia

\section{K. J. Coughlan}

Faculty of Environmental Sciences, Griffith University, Nathan, Queensland, Australia

\section{B. Fentie}

Queensland Department of Natural Resources, Mines and Energy, Meiers Road, Indooroopilly, Queensland, Australia

Received 30 July 2004; accepted 22 November 2004

* Corresponding author: C. W. Rose, Faculty of Environmental Sciences, Griffith University, Nathan, Queensland 4111 Australia.

E-mail address: c.rose@griffith.edu.au 
Earth Interactions - Volume 9 (2005) - Paper No. 5 - Page 2

\begin{abstract}
At the Visayas State College of Agriculture (ViSCA) on the island of Leyte in the Philippines, hydrologic and soil-loss measurements were recorded for 32 erosion events over $3 \mathrm{yr}$ on three 12-m-long bare soil plots with slopes of approximately $50 \%, 60 \%$, and $70 \%$. Measurements included rainfall and runoff rates at 1-min intervals, total soil lost per event from the plot, rill details when observed after an erosion event, and soil settling-velocity characteristics. Storm events are characterized by high rainfall rates but quite low rates of runoff, because of the consistently high infiltration rate of the stable clay soil (an Oxic Dystropept). Both observation and modeling indicated that overland flow is commonly so shallow that much of the soil surface is likely to be unsubmerged. For the $70 \%$ slope plot, half the events recorded mean sediment concentrations from 100 to $570 \mathrm{~kg} \mathrm{~m}^{-3}$. A somewhat constant hydrologic lag between rainfall and runoff is used to estimate a Manning's roughness coefficient $n$ of about $0.1 \mathrm{~m}^{-1 / 3} \mathrm{~s}$, a value used to estimate velocity of overland flow. Possible effects of shallow flows and high sediment concentrations on existing erosion theory are investigated theoretically but are found to have only minor effects for the ViSCA dataset. A soil erodibility parameter $\beta$ was evaluated for the data whenever rilling was recorded following an erosion event. The values of $\beta$ indicate that, except for events with higher stream powers, other erosion processes in addition to overland flow could have contributed to soil loss from erosion plots in a significant number of events.
\end{abstract}

KEYWORDS: Steep-slope erosion; Humid Tropics; Soil erosion model; Shallow flows

\title{
1. Introduction
}

The pressure of population, among other factors, is leading to increased cultivation of tropical steeplands, generally defined as land with slope exceeding $20 \%$. Liao and $\mathrm{Wu}$ (Liao and $\mathrm{Wu} 1987$ ) surveyed the literature concerning cultivated steeplands, finding that severe erosion commonly results when steeplands are converted to intensive arable use. These issues of soil erosion and conservation are of great importance to the Philippines [(the Philippine Council for Agriculture, Forestry and Natural Resources Research and Development) PCARRD 1992; (the Food and Agriculture Organization of the United Nations) FAO 1988], where 59\% of the country has slopes of $18 \%$ or greater and bare soil cultivation is common (World Bank 1989).

Most research on water erosion of soil and soil-conserving practices has been carried out on land with slopes less than about $20 \%$, so that basic research on steepland erosion processes is relatively limited (Lal 1990). However, there have been investigations in the Tropics on the effect of slope steepness on soil loss (e.g., Dangler and El-Swaify 1976), generally indicating a somewhat exponential increase in soil loss with slope steepness (Roose 1977). Much of this research has been in the context of determining the slope length/slope steepness factor in the Universal Soil Loss Equation (Wischmeier and Smith 1978), which does not seek to describe erosion processes as do more recent models that seek some degree of physical realism (Nearing et al. 1989; Rose et al. 1994; Morgan et al. 1998; Rose 1998).

This paper reports the results of soil erosion research carried out at the Visayas State College of Agriculture (ViSCA) on the island of Leyte in the Philippines. 
Earth Interactions - Volume 9 (2005) - Paper No. 5 • Page 3

Hydrologic and soil erosion data for very steep, uniform slope, soil erosion plots are presented for a 3-yr period. These plots were kept bare by frequent hand cultivation and weeding.

Interpretation of the erosion data is sought in terms of soil erodibility. Both rainfall and overland flow are expected to contribute to soil erosion in these experiments. Physically based models have been developed to describe erosion driven by rainfall impact (Hairsine and Rose 1991) and also by overland flow (Hairsine and Rose 1992a; Hairsine and Rose 1992b). However, as shown by Rouhipour (Rouhipour 1997), there can be important interactions between rainfall and flow-driven erosion processes that make it inappropriate to simply add the contributions from each source.

Because it is able to acknowledge the contribution to erosion from any source, such as a combination of rainfall and overland-flow processes, in this paper the general methodology of Yu et al. (Yu et al. 1997b) and Yu and Rose (Yu and Rose 1999) is followed. This methodology uses a calculation of sediment concentration at the transport limit, using the theory of Hairsine and Rose (Hairsine and Rose 1992b). However, there are doubts on the ability of this theory to apply adequately under the extreme conditions of very high sediment concentration and shallow flow typical of the high-slope experiments at the ViSCA site. Therefore, this uncertainty is investigated by enhancing the original theory of Hairsine and Rose (Hairsine and Rose 1992a; Hairsine and Rose 1992b) so as to acknowledge the specific effects of these extreme conditions, and the consequence of this enhancement on erodibility prediction is evaluated by comparison with the simpler original theory.

\section{Materials and methods}

The instrumented runoff plots were located at a site on the ViSCA campus on the Philippines island of Leyte $\left(10^{\circ} 44^{\prime} \mathrm{N}, 124^{\circ} 48^{\prime} \mathrm{E}\right.$, altitude $30 \mathrm{~m}$ above sea level), where the average annual rainfall, dominantly from convective storms, is 2240 $\mathrm{mm}$. A range of experiments investigated the effect of various farm practices on soil loss as described by Presbitero et al. (Presbitero et al. 1995). The data used in this paper are from three bare soil plots, each $6 \mathrm{~m}$ in width with a downslope length of $12 \mathrm{~m}$, but with slopes of 50.4\%, 61.6\%, and 68.7\%, respectively (Figure 1). The plots were hydrologically defined by concrete barriers and kept bare of vegetative cover by manual weeding interspersed between manual cultivation by hoe or shovel following typical farmer practice in the region. All bare soil plots (at three slopes) were weeded on 14 occasions during the experimental period with assistance from a "bolo" or large-bladed knife. Also, on eight occasions, hand cultivation was carried out using a shovel driven into the ground to about $0.15 \mathrm{~m}$, and soil placed just upslope of its removal site. When rills were formed during highly erosive events, and survived after completion of the erosion event, information was collected on rill dimensions and density. Rills were subsequently removed by hand hoe cultivation, thus avoiding flow through preexisting pathways in a following storm event. If there was significant accumulation on the soil surface of what appeared to be fine sediment, cultivation using a shovel was also carried out, leaving the surface with a rough appearance. 


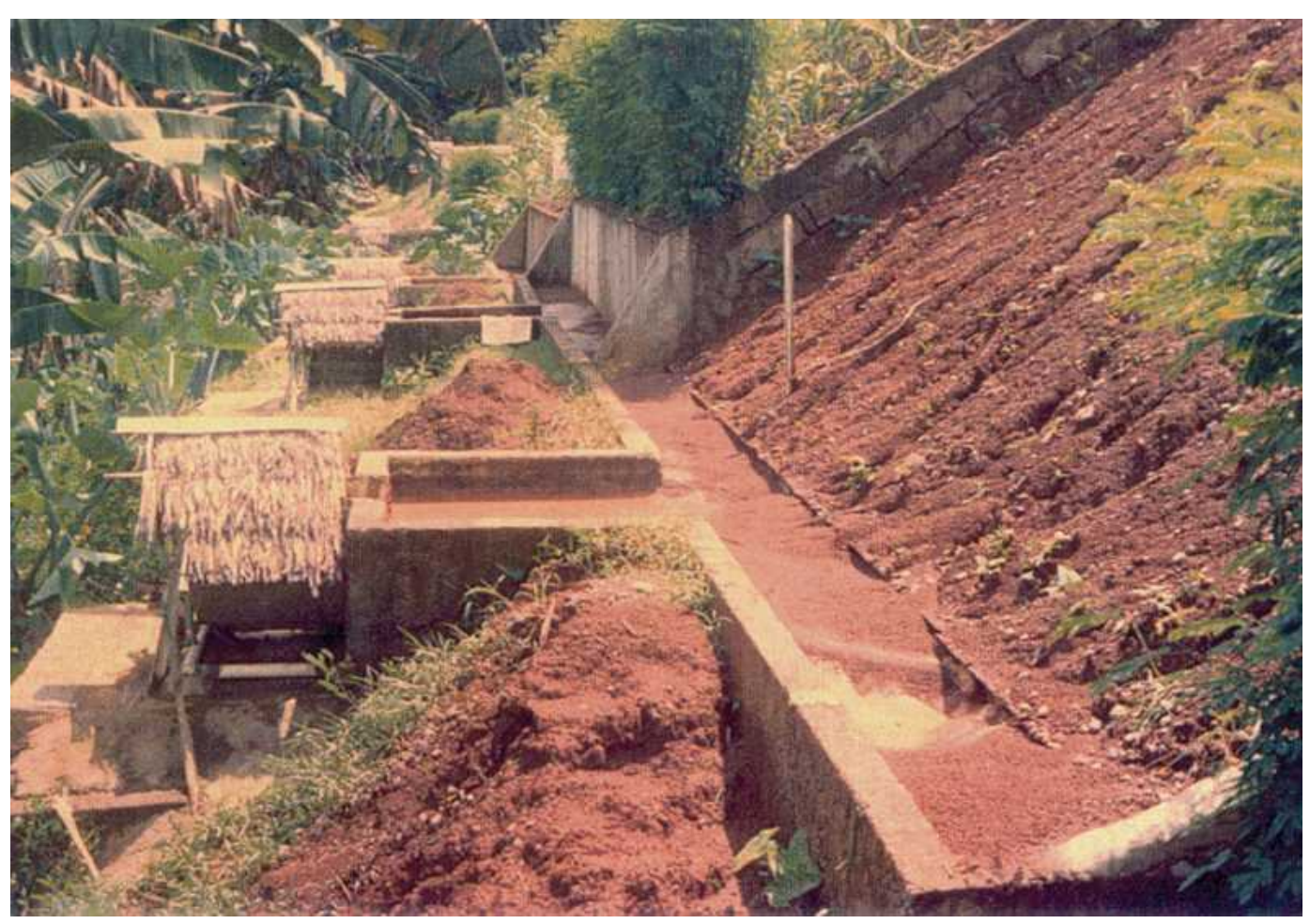

Figure 1. Runoff plots at 70\% slope. Bare plot in the foreground shows rill development with eroded sediment deposited in the Gerlach trough. The row of thatched covers to the left of the photograph are above each plot's tipping-bucket runoff-rate-measuring equipment and suspended load sampler.

The experimental methodology for measuring soil loss and runoff rate from plots has been described in detail by Ciesiolka et al. (Ciesiolka et al. 1995) and Ciesiolka and Rose (Ciesiolka and Rose 1998), and illustrated in Figure 1. Briefly, water and sediment were collected by a concrete modified Gerlach trough that defined the lower end or exit of the experimental runoff plot. The low-slope trough acted as a settling basin in which the coarser sediment (the "bedload") was deposited (Figure 1). Sediment suspended in the runoff water was subsampled, allowing calculation of the event "suspended load," which, combined with the bedload, gave the total event soil loss. The rate of rainfall and runoff was measured at 1-min intervals using tipping-bucket technology with electronic recording (Bonell and Williams 1987).

A modified Gerlach collecting trough installed across the hillslope could act as an impediment to subsurface flow, even possibly leading to exfiltration if a saturated soil zone was formed upslope of the trough. If this were to occur, interpretation of experimental data would be difficult and probably uncertain. To investigate whether or not this possibility would occur at the ViSCA experimental site, subsurface throughflow measuring equipment was installed on the $50 \%$ and $60 \%$ slope bare soil plots. This installation involved removing a $0.5-\mathrm{m}$-wide section of 
Earth Interactions - Volume 9 (2005) - Paper No. 5 - Page 5

soil at the upslope edge of the concrete trough. An agricultural drainage pipe was then installed at a depth of about $0.2 \mathrm{~m}$, supported by a metal plate (in the case of the $50 \%$ slope bare plot), or by concrete (for the $60 \%$ plot). The pipe was then covered above by a porous metal screen, backfilled with soil (60\% plot), or a shallow layer of gravel and then soil (50\% plot). Each pipe was then connected to a small tipping-bucket flow-measuring device similar to that shown in Ciesiolka and Rose (Ciesiolka and Rose 1998).

To evaluate the magnitude of rainfall-driven erosion processes to the sediment load, soil loss from detachment trays of the type illustrated in Rose (Rose 1993) was measured for each erosion event.

The soil type is an Oxic Dystropept, with igneous (mostly basaltic) rock as the parent material, characterized by high infiltration rate and good structural stability. This friable clay soil is representative of soils found on the western side of the island of Leyte. More detail of the soil type is given by Presbitero et al. (Presbitero et al. 1995).

The settling-velocity characteristic of surface soil sampled from the runoff plots was measured using the modified bottom-withdrawal tube technique of Lovell and Rose (Lovell and Rose 1988), with results analyzed using the program described by Lisle et al. (Lisle et al. 1996). The results, given in Figure 2, show the percentage of sediment by mass that settles with a velocity less than any velocity

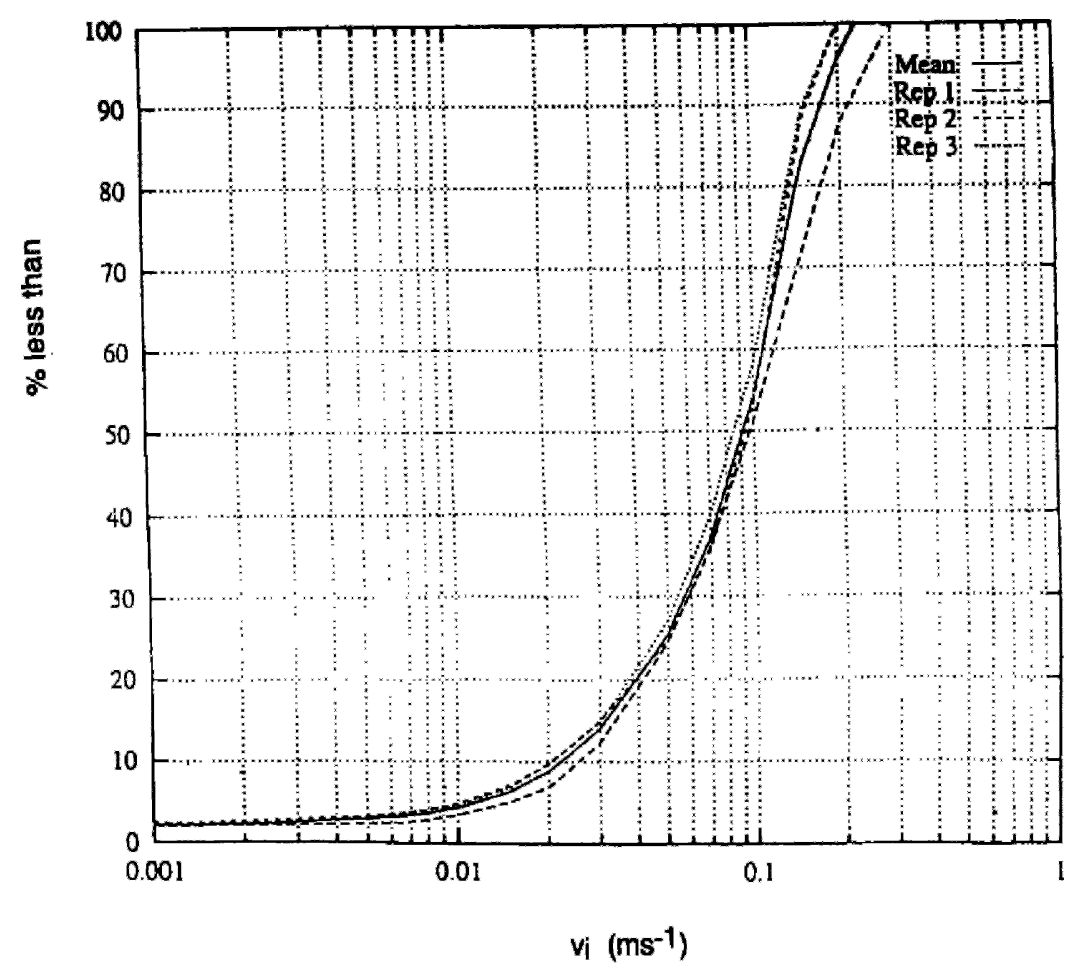

Figure 2. The settling-velocity characteristic of surface soil at the experimental site. Results are shown for three replicates and the mean characteristic used in the calculation. 
nominated on the abscissa. For example, $55 \%$ of sediment had a settling velocity, $v_{i}$, of $0.1 \mathrm{~m} \mathrm{~s}^{-1}$ or less.

An important quantity in the erosion theory employed in erodibility analysis is the velocity of overland flow $V$. Frequent lightning strikes in the tropical rainfall at the ViSCA site made it unsafe to make measurements of flow velocity or depth, as available techniques for such measurement required human presence during the storm event. To calculate $V$ from measured quantities, a measure of soil roughness is required. The measure chosen is Manning's roughness coefficient, denoted $n$, to which $V$ is related by

$$
V=\frac{S^{0.5}}{n} R_{h}^{2 / 3},
$$

where $S$ is land slope (the sine of the angle of inclination), and $R_{h}$ is the hydraulic radius in channelized flow (equal to depth of flow $D$ in sheet flow; Robertson et al. 1988). From analyses of 40 months of rainfall and runoff data, Yu et al. (Yu et al. 2000) showed it is valid to use Manning's equation for describing overland flow during natural rainfall events. Yu et al. (Yu et al. 2000) also showed that Manning's $n$ is related to the time lag $\kappa$ between a burst of rainfall falling on a land surface and its appearance at the end of a runoff plot as a burst of runoff, the relationship being

$$
n=\frac{S^{0.5}}{L}\left(\frac{8 \kappa}{5}\right)^{5 / 3} Q^{2 / 3} .
$$

The lag time $\kappa$ was determined as an average value for 10 runoff events measured on plots for which $L=11.9 \mathrm{~m}$ with a $50.4 \%$ slope $(S=0.4498)$. [These events were those used in $\mathrm{Yu}$ et al. (Yu et al. 1997a).] The average lag time was 2.6 min. The question remains as to the most appropriate value of $Q$ to use in Equation (2), which, together with the average value of $\kappa$, allows estimation of an average value of $n$ for use in the erosion analyses. One appropriate value of $Q$ is the effective runoff rate, $Q_{e}$ (Ciesiolka et al. 1995), which is a flux-weighted average value of runoff rate defined by

$$
Q_{e}=\left(\frac{\Sigma\left(Q^{1.4}\right)}{\Sigma Q}\right)^{2.5}
$$

where $\Sigma$ refers to a summation for the event. (Symbols are defined in appendix C.)

The most appropriate value of $Q$ to use in Equation (2) may be assumed to lie somewhere between $Q_{e}$ [Equation (3)] and the average peak value of $Q$, to which erosion is often related. For the 10 chosen runoff events used in Yu et al. (Yu et al. 1997a), the average value of $Q_{e}$ was $4.3 \mathrm{~mm} \mathrm{~h}^{-1}$, yielding a value of $0.06 \mathrm{~m}^{-1 / 3} \mathrm{~s}$ for Manning's $n$ using Equation (2). The corresponding mean peak value of $Q$ was $12.3 \mathrm{~mm} \mathrm{~h}^{-1}$, which yielded Manning's $n$ of $0.13 \mathrm{~m}^{-1 / 3} \mathrm{~s}$.

The heuristic theory developed by Lawrence (Lawrence 1997) provides conceptual support for an approximate constancy in Manning's $n$ in the circumstances of these experiments. Based on the hydrologic analysis of ViSCA data, a single constant value of Manning's $n=0.1 \mathrm{~m}^{-1 / 3} \mathrm{~s}$ was adopted for use in all events to calculate flow velocity and depth, a value lying between these two estimates, but closer to that based on peak flows. It is likely that the observed lag times will be 
dominantly affected by flow in rills or preferred pathways, so that the adopted value of $n$ should be appropriate for erodibility analysis, given later, which is restricted to those erosion events following the rills that were observed and measured. This value of $n\left(0.1 \mathrm{~m}^{-1 / 3} \mathrm{~s}\right)$ is included in a tabulation of values of Manning's $n$ by Engman (Engman 1986) for plots that were "chisel ploughed and had minor residue rates" (probably the closest similarity in his tabulation to the surface condition of plots in the ViSCA experiments).

Using this value of $n$ in Equation (1) and combining this with mass conservation of water provides the two equations required to determine the two unknowns, $V$ and $R_{h}$.

Presbitero et al. (Presbitero et al. 1995) gives further details of the experiments, and gives data on event rainfall and on event runoff and soil loss for plot treatments other than the bare soil treatments considered in this paper. Data collected from the three steep bare plots used in this paper include rainfall and runoff rates (measured at 1-min time intervals), total storm event soil loss, and rill observations made subsequent to each event in which rills were evident.

Yu et al. (Yu et al. 1997b) and Yu and Rose (Yu and Rose 1999) describe the Griffith University Erosion System Template (GUEST) methodology used in analyzing the results, with program implementation details being given in $\mathrm{Yu}$ and Rose (Yu and Rose 1997) and Fentie et al. (Fentie et al. 1999), the program version being GUEST 3.0. The GUEST methodology enables evaluation of possible erosion enhancement by processes other than those due to overland flow by calculating the maximum possible sediment concentration due to flow alone, a concentration called the transport limit. This paper compares a calculation of the transport limit using the original theory of Hairsine and Rose (Hairsine and Rose 1992b) with an enhancement of that theory designed to cope more effectively with extreme erosion conditions, such as those experienced at the steep tropical ViSCA site. These conditions, which include very high sediment concentrations and shallow overland flow, are acknowledged in the GUEST methodology, using enhancements explained and detailed in appendixes A and B of this paper. The effect of this theory development on erosion analysis is also presented in the following section.

\section{Results and analysis}

With the exception of the 50\% slope plot during Typhoon Uringi (4-6 November 1991), when the total rainfall was $308 \mathrm{~mm}$ and overland flow was $14.9 \mathrm{~mm}$, the total flow collected by the throughflow-measuring installation described in section 2 was very small. Excluding this unusual record, the event mean for total collected throughflow was $0.4 \mathrm{~mm}$ for the $50 \%$ slope plot, with a standard deviation of $0.1 \mathrm{~mm}$. The corresponding mean and standard deviation for the $60 \%$ slope plot

was 0.1 and $0.03 \mathrm{~mm}$, respectively, the mean value being approximately the limit of measurement resolution.

The senior author was able to observe and photograph a number of erosion events at the experimental site. Especially if this event occurred during daylight, the soil surface seemed to shine during runoff, appearing as if it was entirely covered with some sort of reflective plastic sheet. On occasions where no rilling was obvious, the water depth appeared to be so low that it could hardly be seen, 
Earth Interactions - Volume 9 (2005) - Paper No. 5 - Page 8

despite visually obvious delivery of eroded sediment into the Gerlach collection trough. Such observation also indicated that erosion was apparently taking place from the entire area of the erosion plot, and observations of the soil surface made soon after erosion events by other authors agreed with this conclusion.

Table 1 provides summary data on rainfall, runoff, and average sediment concentration of the runoff for 32 erosion events recorded over a 3-yr period for the three bare plots with slopes of approximately 50\%, 60\%, and 70\%. For each recorded event, Table 1 gives total rainfall amount $\left(P_{t}\right)$, and mean $\left(P_{m}\right)$ and peak $\left(P_{p}\right)$ rainfall rates. For each of the three plots of different slopes, two measures of runoff are given, together with the mean sediment concentration for the erosion event, $c$. Here $Q_{t}$ is the total runoff, and $Q_{e}$ the effective runoff rate defined in Equation (3).

Of the 96 plot event records given in Table 1, 42 were recorded as having no rills evident on inspection after the runoff event, each event being typically due to a convective storm accompanied by lightning. On one of the few occasions when it was possible and safe to be present at the experimental site and make observations, it was noted that rills active during the runoff event were not evident at its termination, due to "drowning" of rills with sediment toward the end of the event. Thus, the 42 events recorded as exhibiting an essentially plane or unrilled soil surface after the event probably do not provide a realistic description of the eroding soil surface during the erosion event. Indeed, some broad preferred pathways of runoff could be expected to have existed (Abrahams et al. 1989), even if not noticeable on the plot surface after the event.

The expected contribution of rainfall detachment as an erosion mechanism was estimated by comparing the concentration of sediment shed from the detachment trays referred to in the previous section with the concentration of sediment from the runoff plots. The average value of this concentration ratio was 0.18 . This result may be interpreted as indicating that overland flow, rather than rainfall impact, was the dominant erosion process. However, as will be shown later, flow depths were typically shallow, so that under the typically intense rainfall, rainfall impact would ensure that the threshold for flow-driven erosion was exceeded as well as contributing in its own right to sediment concentration.

Depths of flow were typically shallow. For the $60 \%$ slope bare plot, for example, the maximum and minimum calculated water depths in rills were 4.9 and $0.68 \mathrm{~mm}$, respectively. These shallow calculated water depths are somewhat consistent with visual observations by the senior author recorded earlier. Even this maximum flow depth of $4.9 \mathrm{~mm}$ in rills was less than the larger measured aggregate size for the soil-a little over $6 \mathrm{~mm}$. Though the effective organization of aggregates within rills is unknown, it is possible that even within rills (and certainly in inter-rill regions), the depth of flow is generally inadequate to submerge all aggregates.

\subsection{Effects of shallow-water depths on erodibility analysis}

There are two related consequences of shallow-water depths on erodibility analysis involving the soil's settling velocity characteristics given in Figure 2. First, unsubmerged soil aggregates cannot take part in the process of deposition. This implies that the average velocity of settling of soil aggregates $(\phi)$ is reduced, 
Earth Interactions - Volume 9 (2005) - Paper No. 5 - Page 9

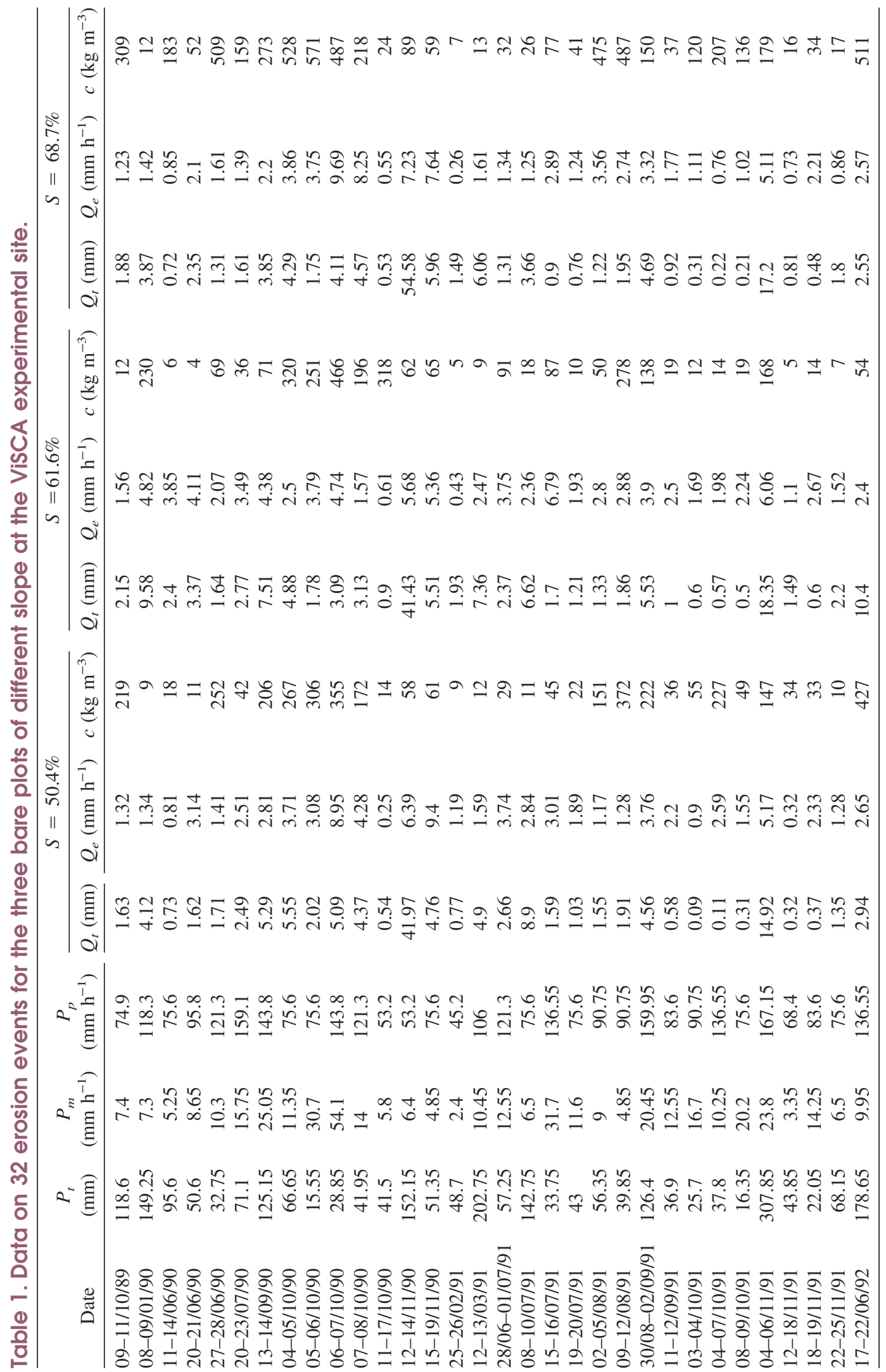


Earth Interactions - Volume 9 (2005) - Paper No. 5 • Page 10

and must be replaced by a lower effective value $\left(\phi_{e}\right)$, as explained in Rose et al. (Rose et al. 1997), and illustrated in Fig. A1. For soil at the ViSCA site, $\phi=0.105$ $\mathrm{m} \mathrm{s}^{-1}$ (Figure 3), and in these experiments, $\phi_{e} / \phi$, which depends on flow depth, varied from 0.26 to 0.88 as flow depth in rills varied from minimum to maximum values, respectively. Second, shallow flows also leave larger aggregates unsubmerged, even in shallow rills (Fig. A1). Thus overland shallow flows do not cover the entire soil surface, but take place between unsubmerged aggregates, which effectively provide a protecting fractional coverage of the soil surface. The detailed microtopography of sediment distribution at the soil surface will be dynamic and, in general, unknown. However, the time history of flow depth during an erosion event can be calculated from data collected in the ViSCA experiments, and the typical size distribution of soil aggregates is known. Thus, it is possible to make an estimate, however crude, of the fractional coverage $C$ of the soil surface by those aggregates that are not inundated by overland flow in these experiments. This leaves a fraction $(1-C)$ of the soil surface occupied by submerged and therefore potentially erodible soil aggregates. One possible model for obtaining an estimate of $(1-C)$ is given in appendix A [Equation (A7)].

\subsection{Effects of high sediment concentration on erodibility analysis}

We now turn to a second significant and less commonly reported feature illustrated by the ViSCA data, namely, unusually high values of the measured event

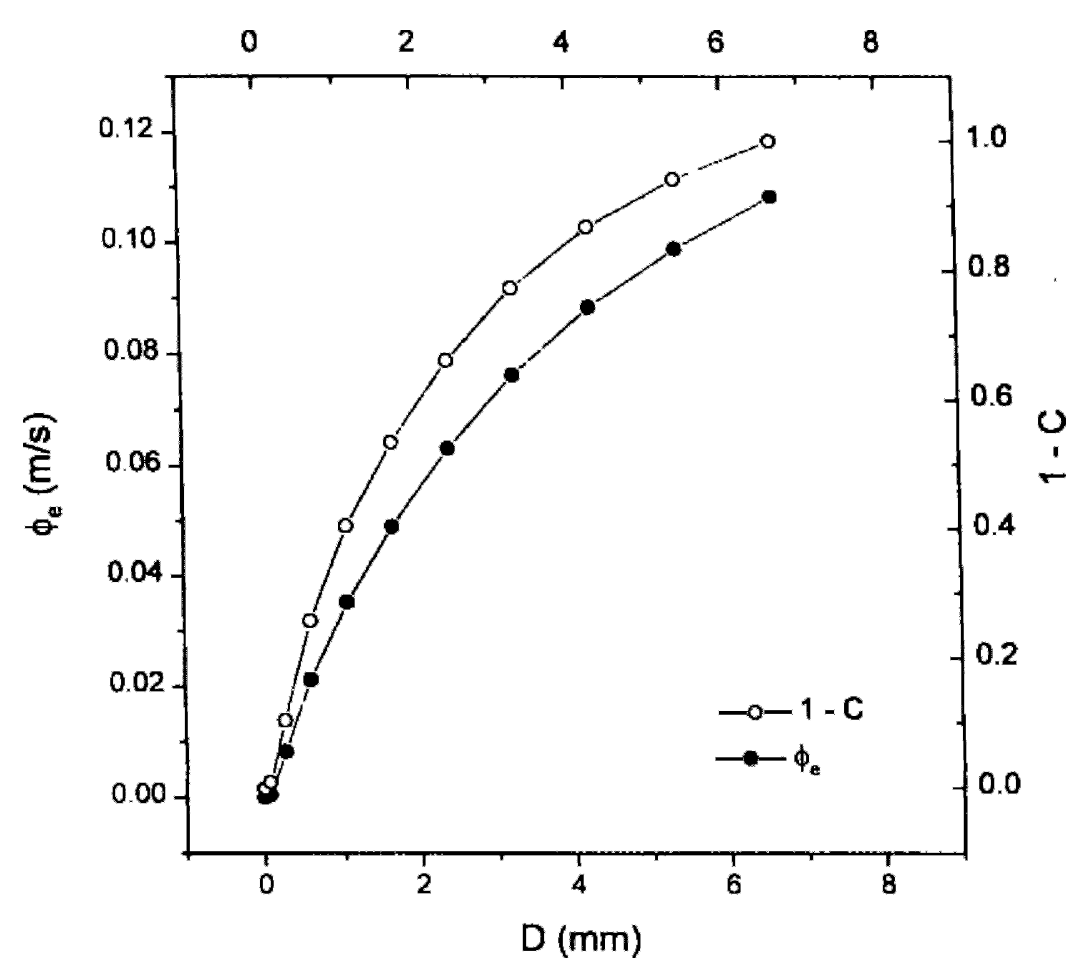

Figure 3. The dependence on the water depth $D$ of the effective depositability $\left(\phi_{e}\right)$, and the exposure fraction $(1-C)$ for soil at the experimental site. For $D \geq$ $6.64 \mathrm{~mm}, \phi_{e}=\phi=0.1083 \mathrm{~m} \mathrm{~s}^{-1}$, and $(1-C)=1$ or $C=0$. 
mean sediment concentration $c$. Table 1 shows that a high value of $c$, well over $100 \mathrm{~kg} \mathrm{~m}^{-3}$, is common, no doubt partly due to the high slopes involved. There are two consequences of high sediment concentrations, not examined in previous models of soil erosion, but whose effect on calculated magnitudes should be explored.

The first consequence is the continuing call that must be made on the shear stress exerted by the overland flow in order to provide momentum to sediment in its removal from the soil surface; this acquired momentum being lost in return to the soil surface in saltation. This call reduces the shear stress available for erosion, and was termed a "saltation stress" by Bagnold (Bagnold 1941) in developing wind erosion theory where this stress is very important. Theory for this stress is developed in appendix B [Equation (B10)], and, as shown in the appendix Equations (B12) and (B14), the effect of this stress is to reduce the total shear stress to the effective value $\tau_{s}$ given by Equation (B14).

The second consequence of high sediment concentrations is to increase the effective density of the sediment-laden fluid significantly beyond that of water $(\rho)$. Since fluid density is involved in calculating the shear stress exerted by water flowing over a soil bed, $\rho$ must be replaced by the readily calculated actual or effective density of sediment water mixture $\rho_{e}$. As shown in Rose et al. (Rose et al. 1997), to a good approximation

$$
\rho_{e}=\rho+\eta c
$$

where $\eta$ is commonly about 0.62 but depends on the density of the suspended particles.

Combining expressions for the effect of both shallow-water flow and saltation stress concentrations into the original equation of Hairsine and Rose (Hairsine and Rose 1992b) for the sediment concentration at the transport limit $c_{t}$ [denoted $\left.c_{t}(\mathrm{HR})\right]$, it can be shown that their effects can be represented by a factor $K_{1}$, where

$$
K_{1}=\frac{F b V^{2}(1-C)}{g D}
$$

and the rill geometry factor $b$ is given by $\mathrm{Yu}$ and Rose (Yu and Rose 1999).

Incorporating also the effect of the increase in density to $\rho_{e}$ [Equation (4)] at high sediment concentrations, this can be shown to be represented by a second factor $K_{2}$ where

$$
K_{2}=\frac{\eta F b R_{h} S V(1-C)}{D \phi_{e}}\left(\frac{\sigma}{\sigma-\rho}\right) .
$$

Note that both $K_{1}$ and $K_{2}$ are dimensionless.

Following algebraic manipulation (given by Presbitero 2003), it follows that the expression for the sediment concentration at the transport limit $c_{t}$, modified by all the effects described, is given by

$$
c_{t}=\frac{F b\left(\frac{\sigma}{\sigma-\rho}\right)(1-C)\left(\rho g R_{h} S V-\Omega_{\mathrm{o}}\right)}{g D \phi_{e}\left(1+K_{1}-K_{2}\right)},
$$


Earth Interactions - Volume 9 (2005) - Paper No. 5 - Page 12

which can be conveniently written in the following form:

$$
c_{t}=\frac{c_{t o}}{\left(1+K_{1}-K_{2}\right)}=c_{t}(\mathrm{HR}) \frac{\phi(1-C)}{\phi_{e}\left(1+K_{1}-K_{2}\right)},
$$

where $K_{1}$ and $K_{2}$ are given by Equations (5) and (6), where the definition of $c_{t o}$ follows from Equations (7) and (8), and $(1-C)$ by Equation (A7). A full derivation of these equations is given in Presbitero (Presbitero 2003), and $c_{t}(\mathrm{HR})$ is derived in Hairsine and Rose (Hairsine and Rose 1992b).

\subsection{Quantitative evaluation of the effects of high sediment concentration and shallow-water depth on flow-driven erosion theory}

While the possible effects of shallow flows and high sediment concentration on flow-driven erosion theory are of general interest, their quantitative significance on flow-driven erosion theory will be illustrated using the ViSCA dataset (Table 1).

Figure 3 shows the variation of factors $\phi_{e}$ and $(1-C)$ with depth $D$ of water. As shown in Equation (7), what is important to $c_{t}$ is not the individual values of $\phi_{e}$ or $(1-C)$, but the ratio $(1-C) / \phi_{e}$.

For each event in Table 1, Figure 4 shows the values of the adjustment factors $K_{1}$ and $K_{2}$ from Equations (5) and (6), respectively; for clarity $K_{1}$ and $K_{2}$ are plotted against flow velocity $V$, on which factor, among others, they depend. The magnitude of $K_{2}$ always exceeds that of $K_{1}$ for data from this site.

A combined adjustment factor $K$ can be defined as

$$
K=1+K_{1}-K_{2},
$$

which incorporates the effect of both saltation stress and enhancement of fluid density by sediment. Figure 5 shows $K$ also as a function of calculated mean flow velocity $V$.

The values of $c_{t}$ for the ViSCA data were calculated using Equation (7) [with (5) and (6)]. These values of $c_{t}$, which include enhancement to the theory of Hairsine and Rose (Hairsine and Rose 1992b) for the effects described, are plotted as both ordinate and abscissa in Figure 6, thus defining a 1:1 line.

From Equations (8) and (9), $c_{t o}=K c_{t}$, and Figure 6 also shows $c_{t o}$ as ordinate plotted against $c_{t}$ as abscissa. Hence, the differences between the 1:1 line and values for $c_{t o}$ calculated for the three slopes illustrate the effect on $c_{t}$ of the combined factor $K$ given in Equation (9).

Also shown in Figure 6 is the sediment concentration at the transport limit calculated using the original theory of Hairsine and Rose (Hairsine and Rose $1992 \mathrm{~b}$ ), and denoted as $c_{t}$ (HR). None of the enhancement or modification given in appendixes $\mathrm{A}$ and $\mathrm{B}$ is made in calculating $c_{t}(\mathrm{HR})$, for which $\phi_{e}=\phi, C=0$, and $K_{1}=K_{2}=0$. The differences between $c_{t}(\mathrm{HR})$ and $c_{t}$ (given by the 1:1 line) are a little greater than between $c_{t o}$ and $c_{t}$ (Figure 6).

An important conclusion that can be drawn from Figure 6 is that, at least for the ViSCA data, predictions based on the original theory of Hairsine and Rose (Hairsine and Rose 1992b) are affected only in a rather minor way by inclusion of the correction factors developed to cope with the effects of high sediment concentra- 
Earth Interactions - Volume 9 (2005) - Paper No. 5 • Page 13

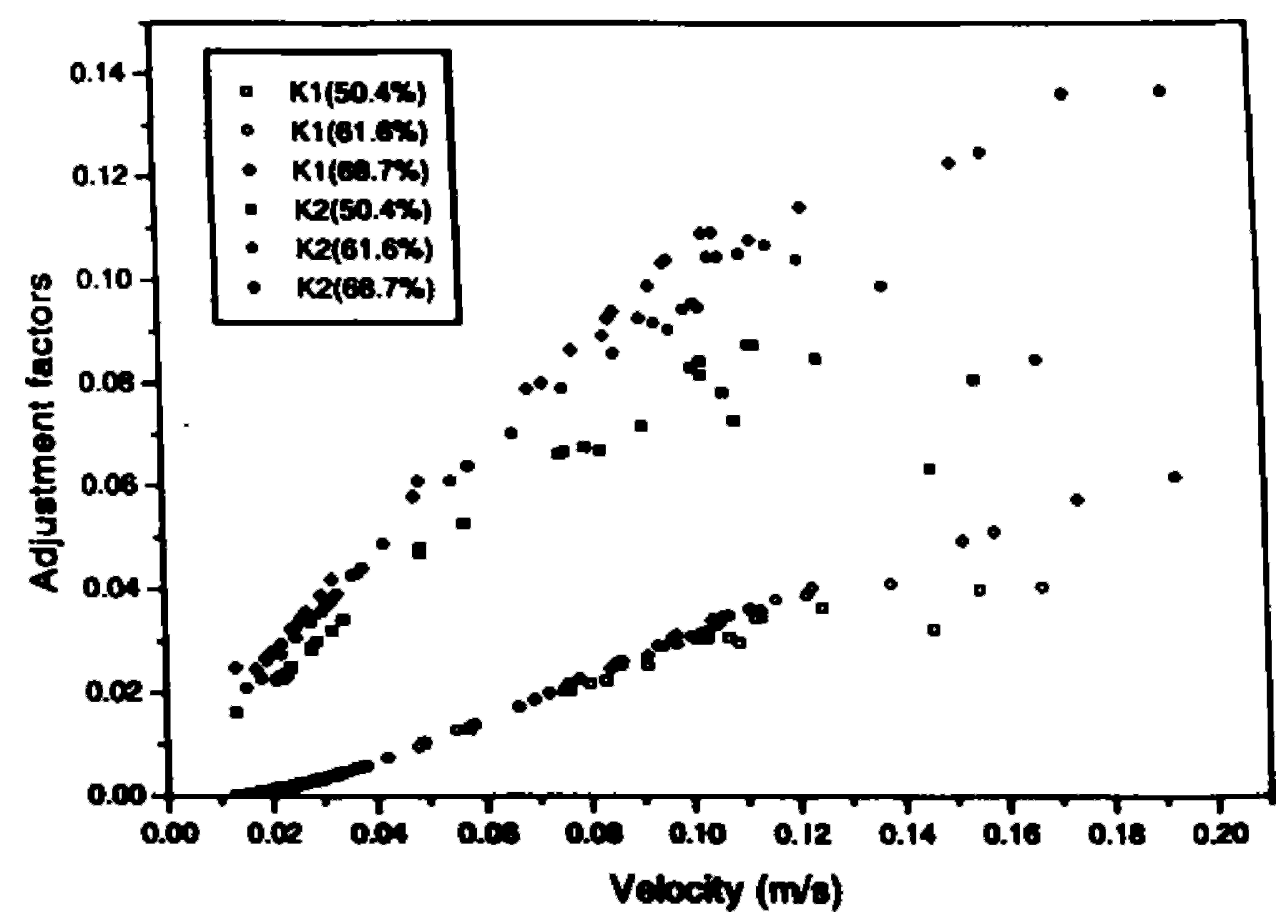

Figure 4. Variation with mean flow velocity in the two adjustment factors, $K_{1}$ (Equation (5)) associated with the effect of saltation stress, and $K_{2}$ reflecting the consequence of fluid density enhancement by sediment (Equation (6)). Different-shaped symbols are used for each of the three plots of different slope.

tion and shallow flows. This is partly due to approximate compensation between factors $K_{1}$ and $K_{2}$, and also compensation between $(1-C)$ and $\phi_{c}$ as shown by Equation (7) and Figure 3. Given the assumptions in the original theory, this outcome may be somewhat fortuitous, or at least could not have been predicted without development of the enhancing analysis, and its application to the ViSCA dataset.

\subsection{Erodibility analysis using GUEST 3.0}

Program GUEST 3.0 (Fentie et al. 1999), and its predictive form called GUEPS (Yu et al. 1997b) both incorporate the correction factors to erosion theory considered in appendixes A and B of this paper. These programs consider the situation where the eroding soil offers some resistance to erosion, in which case the sediment concentration $c$ will be less than its maximum value, the transport limit $c_{t}$. A measure of this resistance is given by the erodibility parameter $\beta$ defined in Rose (Rose 1993) as

$$
\beta=\frac{\ln \bar{c}}{\ln \bar{c}_{t}}
$$


Earth Interactions • Volume 9 (2005) • Paper No. 5 • Page 14

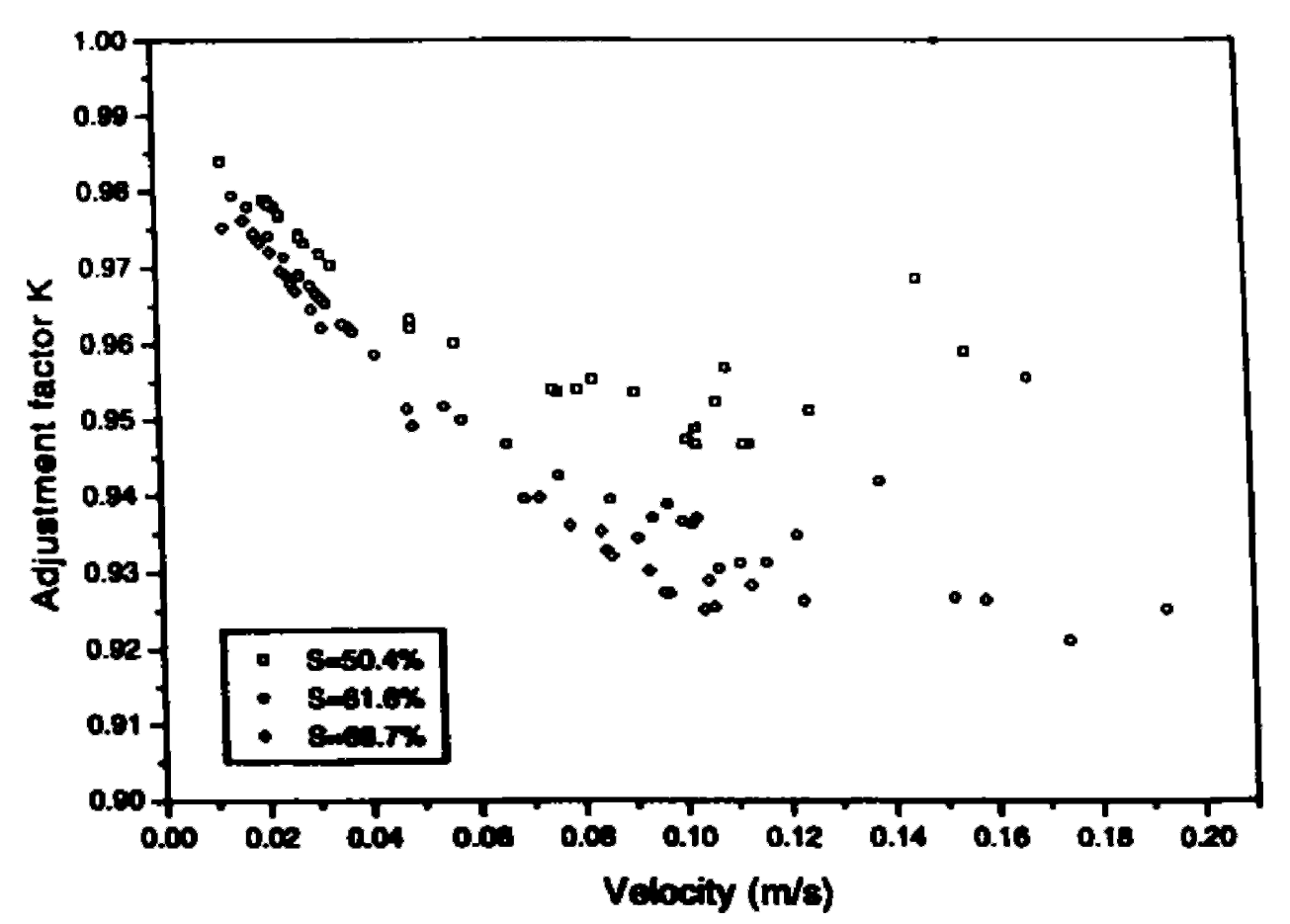

Figure 5. Variation with mean flow velocity in the combined adjustment factor $K(=$ $1+K_{1}-K_{2}$ ) (Equation (9)). Different-shaped symbols are used for each of the three plots of different slope.

where the bar over values of $c$ and $c_{t}$ [calculated using Equations (5) to (7)] indicate average values for any erosion event. In the context where erosion is dominantly driven by overland flow, $\beta$ has a maximum possible value of unity, and the degree to which $\beta<1$ is a measure of the soil's resistance to flow-driven erosion. Program GUEST 3.0 employs $\beta$ defined in Equation (10), both to simplify the original flow-driven theory of Hairsine and Rose (Hairsine and Rose 1992a; Hairsine and Rose 1992b), and to generalize the use of flow-driven theory as a basis for erodibility evaluation. This generalization follows from the ability of the single parameter $\beta$ to incorporate the effect of any process that contributes to erosion (Rose 1993). In the ViSCA experiments, rainfall impact and possibly other processes may well have contributed to erosion as well as overland flow, so the use of $\beta$ in GUEST 3.0 is very appropriate in the analysis of this dataset with its uncertain mix of erosion mechanisms. This integrative erodibility parameter $\beta$ has been widely used in multicountry studies of soil erosion (Soil Technology 1995; Coughlan and Rose 1997).

For 18 out of the 32 erosion events detailed in Table 1, rilling was observed after the rainfall event on the plots for all three slopes. For these $18 \times 3=54$ datasets, the erodibility parameter $\beta$ was calculated. Since the effective surface geometry for flow is unknown for the remaining $14 \times 3=42$ datasets where no rills were recorded, realistic calculation of $\beta$ is not possible. For the rilled dataset, Figure 7 shows the erodibility parameter $\beta$ plotted against the stream power of flow, $\Omega$, where $\Omega$ is given by the term $\rho g R_{h} S V$ in Equation (7). 
Earth Interactions • Volume 9 (2005) • Paper No. 5 • Page 15

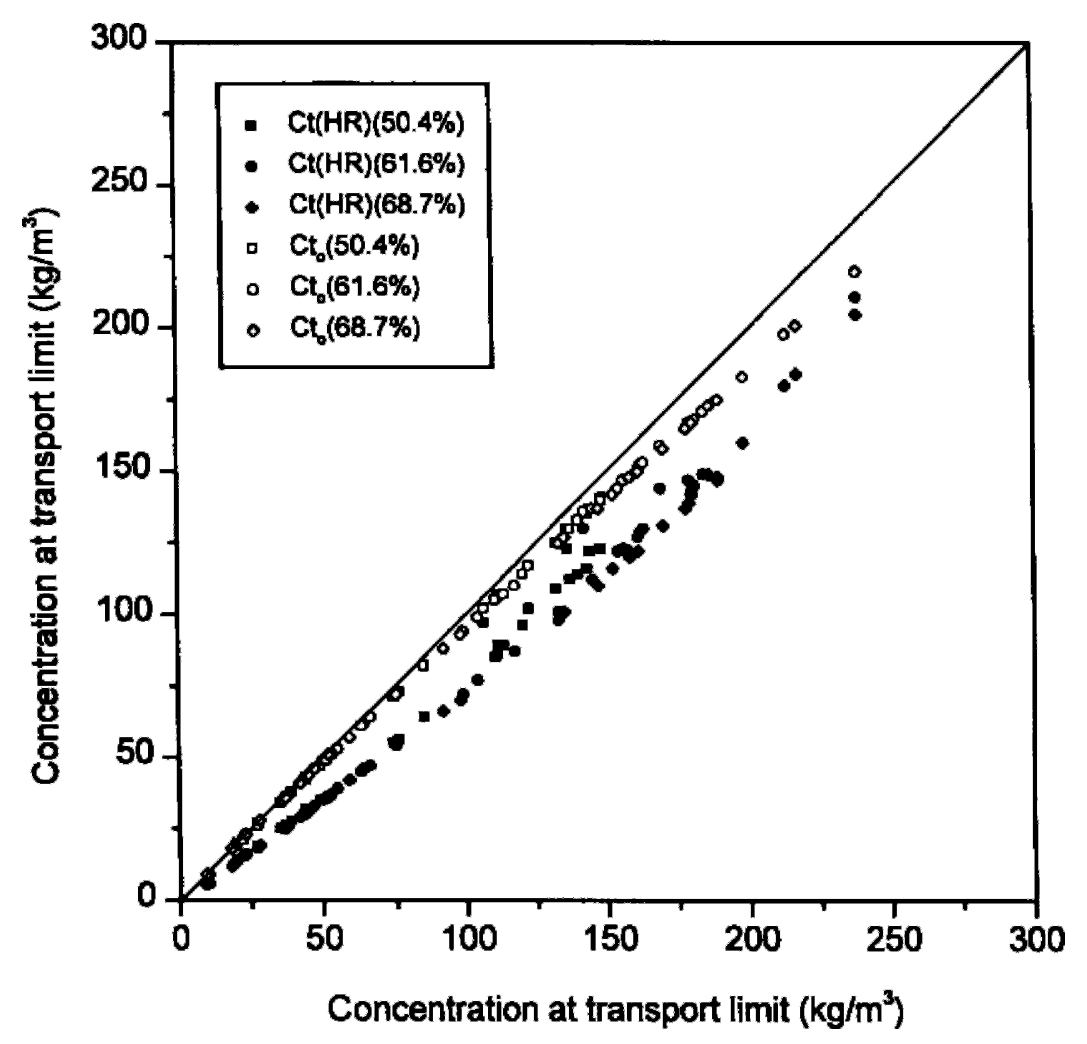

Figure 6. The 1:1 line represents $c_{f}$ calculated using Equation (7) plotted against itself. Also plotted against $c_{f}$ are the ordinate variables $c_{f}(H R)$ (explained in the text), and $c_{t o}$ (Equations (7) and (8)).

\section{Discussion}

The small values given in section 3 for throughflow measured with the installation described in section 2 indicate that exfiltration of subsurface flow intercepted by the Gerlach measuring trough is insignificant. Apparently infiltrated water moves deeply and quickly into the profile of soil at this site.

Reviewing the literature on overland-flow hydraulics for rough surfaces, Lawrence (Lawrence 1997) concluded that a systematic theory for evaluating such surface flow regimes had not yet been developed. The model of the exposure fraction $(1-C)$, given in appendix $\mathrm{A}$, is essentially a generalization of the concepts of Lawrence (Lawrence 1997) over a continuous range of element sizes.

From Equation (7), a significant factor in the calculation of $c_{t}$ is the ratio $(1-C) / \phi_{e}$. From the data given in Figure 2, this ratio varies only by a factor of about 2. Thus, despite the importance of either factor $(1-C)$ and $\phi_{e}$ taken alone, in their ratio each factor approximately cancels the other out, resulting in their ratio having a minimal effect on the calculation of $c_{t}$. This result follows from the model resulting in Equation (A7).

The theory given in appendix B indicates that increasing saltation stress, $\tau_{\mathrm{sa}}$ [Equation (B11)], leads to a decrease in effective surface shear stress [Equation 
Earth Interactions - Volume 9 (2005) • Paper No. 5 • Page 16

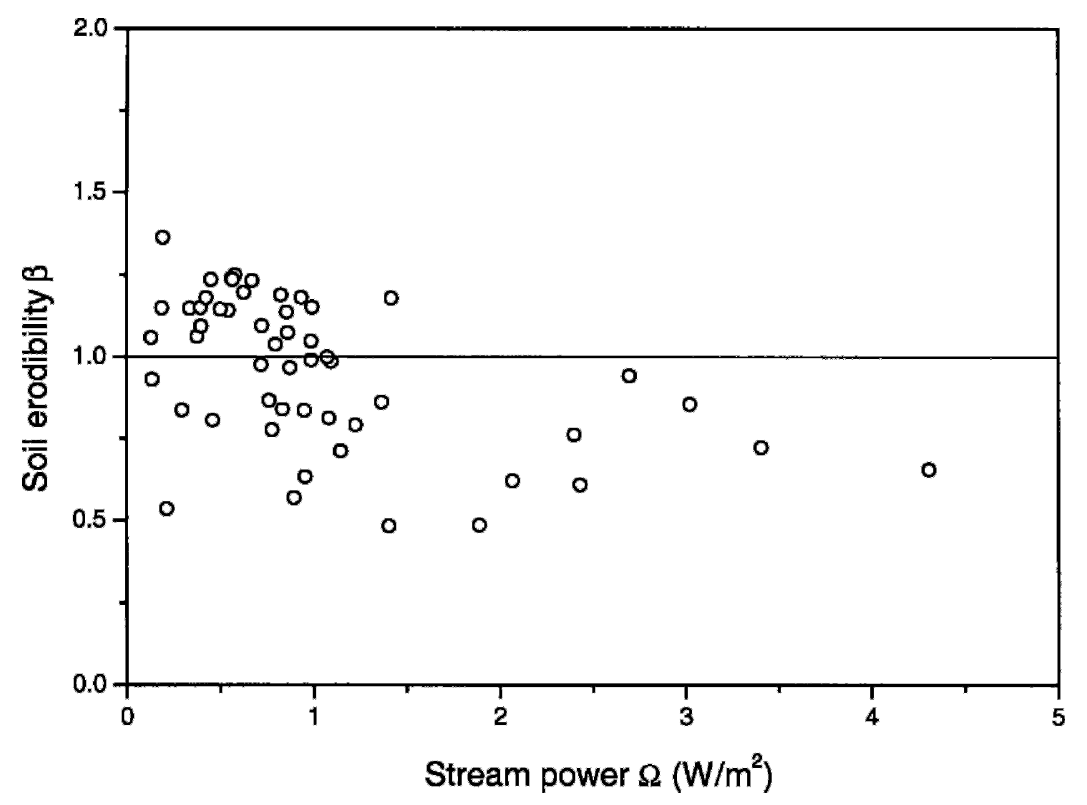

Figure 7. Values of $\beta$ calculated for each erosion event with observed rilling plotted against the mean stream power $\Omega$ for the event.

(B15)], and thus to a decrease in $c_{t}$. This is reflected in the positive sign for $K_{1}$ in the denominator of Equations (7) and (8). In contrast, the enhancement of fluid density at high sediment concentrations should increase shear stress and so $c_{t}$, reflected in the negative sign for $K_{2}$ in Equations (7) and (8). Despite the expected difference in sign, there appears to be no a priori reason why these two effects should be approximately equal and so cancel each other out. For the ViSCA data the overall factor $K$ [Equation (9)] combining both effects varies only between 1 and 0.92 (Figure 5). This small range in departure from unity in the factor $K$, and since $c_{t}=c_{t o} / K$, is why $c_{t o}$ is only a little less than $c_{t}$, as illustrated in Figure 6.

It is demonstrated only for the ViSCA data of this paper that there is very approximate cancellation of $K_{1}$ with $K_{2}$, and of the effects of $(1-C)$ and $\phi_{e}$. The data were obtained in rather extreme situations of very high sediment concentration, high slopes, low runoff rates, and shallow-water depths, even in rills; however, these are all situations where the roles of these newly investigated factors are expected to be more pronounced than would be the case in many field situations. While the effect of these factors can diminish at greater water depths and more modest sediment concentrations, their inclusion in the GUEST and GUEPS family of programs (Yu and Rose 1997; Yu and Rose 1999; Fentie et al. 1999) is designed to enhance their generality of application.

Figure 6 also shows that $c_{t}(\mathrm{HR})$ calculated from the original theory of Hairsine and Rose (Hairsine and Rose 1992b) is somewhat less than $c_{t}$ calculated using Equation (7) for the ViSCA data. The discrepancy between $c_{t}$ and $c_{t}(\mathrm{HR})$ increases with $c_{t}$ (up to about $100 \mathrm{~kg} \mathrm{~m}^{-3}$ ), beyond which $c_{t}$ exceeds $c_{t}(\mathrm{HR})$ by up to about $40 \mathrm{~kg} \mathrm{~m}^{-3}$. While the relationship between $c_{t}, c_{t o}$, and $c_{t}(\mathrm{HR})$ is rather coherent for 
this ViSCA dataset, theory suggests that this relationship could vary with soil type, possibly only to a modest amount, though this needs further investigation.

As mentioned in section 3, rilling during the erosion event may not be evident subsequent to the runoff event, and on one occasion it was observed that sediment collection in rills toward the end of the event left no obvious trace of their activity during the event. Even when well-defined rills were not observed following the event, preferred pathways of flow over the surface of field plots almost certainly would occur. This expectation was supported by spatial variability in the observed pattern of net deposition in the Gerlach trough after events, suggesting the delivery of sediment by flow pathways.

When rills were observed and measured after the erosion event, this information was used to calculate $c_{t}$ and $\beta$. Figure 7 shows significant scatter when $\beta$ is plotted against stream power $\Omega$. The assumption that measurements of the spacing and dimensions of rills made after the erosion event adequately describe the undoubtedly dynamic behavior of rill development (and perhaps in filling) during the erosion event is one likely contributor to such scatter (Fentie et al. 1999). As mentioned in section 2, cultivation was used when rilling patterns showed signs of becoming established. Such management of the bare plots, combined with some possible soil consolidation and/or aggregate breakdown between such disturbance, could be another reason for variation in values of $\beta$.

Detailed investigation of the possible effect on $\beta$ of cultivation or weeding, and the timing of these operations leads to the following general conclusions. If cultivation or weeding, which disturbs the soil surface, was carried out when the soil was wet, then the value of sediment concentration, soil loss, and $\beta$ is reduced for a following storm a few days later. However, as time proceeds, $\beta$ tends to increase. Weeds were pulled out by hand or with the assistance of a large knife, and attached soil was separated and scattered onto the plot before weed removal. If the weeding operation was carried out some time following rainfall, $\beta$ was increased in the subsequent event.

While mechanical cultivation in western systems of agriculture is commonly found to increase erodibility and decrease soil strength (e.g., Ross 1989), hand cultivation by shovel or hoe, especially on moist plots, produced a rough, cloddy, and well-aggregated condition that evidently provided temporary resistance to erosion. It may be conjectured that the gradual increase in erodibility with time that eventually ensued might be due to clod weathering or aggregate breakdown processes, and that weeding in dry conditions made available loose and erodible material on the soil surface. Such possible explanation of the results requires further study, not carried out at the time of the experiments, partly due to event frequency and needed cultivation and weeding activities. Associated changes with time or cultivation in soil settling-velocity characteristics can occur (e.g., Paningbatan et al. 1995), but were not investigated in these experiments.

For rilled events, Figure 7 shows a possible trend for the values of $\beta$ to decline as $\Omega$ increases. At the $30 \%$ slope at the Chiang Rai site in Thailand, Yu et al. (Yu et al. 1999) found that $\beta$ tended to decrease with peak runoff rate from values just above unity to below unity in a manner somewhat similar to that shown in Figure 7 for stream power. If flow-driven erosion dominates, then $\beta$ should not exceed unity (Rose 1993; Soil Technology 1995; Coughlan and Rose 1997). Figure 7 indicates that $\beta$ can exceed unity at stream powers less than about $1.5 \mathrm{~W} \mathrm{~m}^{-2}$, 
Earth Interactions • Volume 9 (2005) • Paper No. 5 • Page 18

which could indicate that some erosion process other than flow may then be contributing to erosion, with rainfall impact being one very likely contender because overland flows were shallow. Even though, on average, the concentration of sediment shed by detachment trays exposed to rainfall was only a small fraction (0.18) of the sediment concentration from runoff plots, any sediment removed from the soil surface by rainfall impact can contribute to that transported from the runoff plot in overland flow. The contribution of any process to net erosion, such as rainfall impact, downslope rolling of aggregates, or mass movement, increases and is incorporated in the value of $\beta$. The erodibility parameter $\beta$ has a clear physical meaning only when flow-driven erosion dominates (Rose 1993).

It is recognized that there are other uncertainties that would influence the calculated value of $\beta$. For example, Manning's $n$ may well vary with flow rate despite the support for use of a constant value given in section 3. Manning's $n$ has a direct though muted effect on the calculated value of $\beta$ (Rose et al. 1997). Furthermore, there may be processes affecting sediment transport in the shallow flows of these experiments other than those acknowledged in the theory presented (Pal et al. 2000).

\section{Conclusions}

Despite commonly high rates and amounts of rainfall at the ViSCA experimental site, quite low to modest rates of runoff per unit area are recorded (Table 1), indicating high and stable rates of infiltration into this bare and frequently cultivated soil. As a consequence of this, and because of the steep slopes involved, the depth of overland flow from the bare soil plots was observed to be very shallow indeed. Nevertheless, considering all 32 recorded erosion events, and the three plots at the three slopes of about $50 \%, 60 \%$, and $70 \%, 38$ out of the $3 \times 32=96$ plot events yielded sediment concentrations higher than $100 \mathrm{~kg} \mathrm{~m}^{-3}$, often considerably higher (Table 1). This combination of high sediment concentrations, shallow flows, and steep slopes presents a challenge to modeling erosion processes.

Most erosion models require knowledge of the velocity of flow $V$ during erosion events. Human safety during tropical storm rainfall at the ViSCA site precluded direct field measurement of $V$, which was evaluated by estimating the magnitude of Manning's roughness factor $n$ (to which $V$ is related). This was estimated using the measured hydraulic lag between peaks of rainfall and runoff on the 12-m-long erosion plots, where this lag was fairly constant at $2.6 \mathrm{~min}$ for varied events. The data converted into a value of $n$ of about $0.1 \mathrm{~m}^{-1 / 3} \mathrm{~s}$.

While the sediment concentration from rainfall detachment trays was only 0.18 , that from the erosion plot (i.e., rainfall-driven erosion processes) is expected to be an important erosion contributor. Thus, the modeling approach illustrated by Yu et al. (Yu et al. 1997a; Yu et al. 1997b) was adopted since this approach uses a soil erodibility parameter $\beta$ whose magnitude is increased by any process that contributes to erosion. This approach is a simplified adaptation and generalization of the more fundamental flow erosion theory of Hairsine and Rose (Hairsine and Rose 1992a; Hairsine and Rose 1992b). The possible effect on the sediment concentration at the transport limit $c_{t}$ predicted by the Hairsine and Rose theory of 
Earth Interactions - Volume 9 (2005) - Paper No. 5 • Page 19

the somewhat extreme erosion situations exhibited by the ViSCA data is investigated theoretically.

The enhanced theory developed in appendixes A and B in order to carry out this investigation was constrained by the practical requirement that only readily measurable soil information should be required for its application. When this enhanced GUEST theory was applied to the ViSCA dataset, it was found that there is a degree of self-compensation between the various effects that arise due to high sediment concentration and shallow flows. The combined effects of these rather extreme conditions recognized in the enhanced calculation of $c_{t}$ are rather limited, so that these values of $c_{t}$ do not differ greatly from those calculated using the original theory of Hairsine and Rose (Hairsine and Rose 1992b) in which these effects were ignored. Nevertheless, the enhanced approach represented by $\mathrm{Yu}$ et al. (Yu et al. 1997b) and Yu and Rose (Yu and Rose 1997) was employed in calculating the single soil-erodibility parameter $\beta$ for those erosion events in the ViSCA datasets for which rills were recorded and measured.

The values obtained for $\beta$ indicate that erosion processes other than those due to overland flow were likely to have made a significant contribution to sediment concentration, especially at lower stream powers, but that flow-driven erosion processes are likely to have been dominant in events with higher stream powers. This conclusion is supported both by the original theory of Hairsine and Rose (Hairsine and Rose 1992b), and by its enhancement made to recognize effects associated with shallow flows and high sediment concentrations.

Acknowledgments. The assistance of funds from the Australian Centre for International Agricultural Research is acknowledged in supporting this project carried out by the Department of Agricultural Engineering and Applied Mathematics on the site of the Visayas State College of Agriculture (ViSCA) of the Philippines. The assistance of M. Escalante, I. Lisle, and J. Banyo is gratefully acknowledged.

\section{Appendix A}

\section{An Effect of Shallow Flow Depth and High Sediment Concentration on the Calculation of $c_{t}$}

Hairsine and Rose (Hairsine and Rose 1992a; Hairsine and Rose 1992b) provide a theory for predicting the sediment concentration at the transport limit $c_{t}$, which assumes submergence of even the largest size aggregate. When this does not occur, this appendix presents a model of the reduction in value of $c_{t}$, which may occur. This model is restricted by the assumption that the only commonly available soil information of relevance is its size or settling-velocity distribution. This information is here used to estimate, for any flow depth $D$, the fractional coverage of the soil surface $C$ by aggregates not inundated by flow. Thus, erosion is assumed to be restricted to the inundated fraction of the surface, $1-C$, for which an expression is now derived in the context of theory for $c_{t}$.

The erosion theory of Hairsine and Rose (Hairsine and Rose 1992a) indicates the transport limit as being achieved when the rates of deposition to and reen- 
trainment from the deposited layer formed on the soil surface are equal. Because rate of deposition increases with sediment size, the deposited layer is richer in coarser material. The approximate assumption will be made that, even in shallow flows, this size enrichment is as described by Equation (18) in Hairsine and Rose (Hairsine and Rose 1992a) for deeper flows. This theory describes the ratio of the mass per unit area in size class $i, M_{d i}$, to its sum over all class sizes $M_{d t}$, which is the total mass per unit area in the surface layer formed by deposition, as given by

$$
\frac{M_{d i}}{M_{d t}}=\frac{v_{i}}{\sum_{i=1}^{I} v_{i}} .
$$

The quantity $M_{d i}$ in Equation (A1) can be expressed as the product of the number of aggregates per unit area in the deposited layer in size class $i, N_{d i}$, and the mass of each aggregate. Similar to the analysis of Lawrence (Lawrence 1997), aggregates will be assumed to be spherical, of diameter $d_{i}$, and of uniform density $\sigma$, so that

$$
M_{d i}=N_{d i}(\pi / 6) \sigma d_{i}^{3} .
$$

Equating the two expressions for $M_{d i}$ given by Equations (A1) and (A2), then

$$
N_{d i}=\frac{6 M_{d t}}{\pi \sigma \sum_{i=1}^{I} v_{i}}\left(\frac{v_{i}}{d_{i}^{3}}\right)
$$

so that

$$
N_{d i} \propto \frac{v_{i}}{d_{i}^{3}} .
$$

Denote by $A_{i}$ the relative cover fraction of the soil surface (viewed in plan) that is provided by aggregates of each class. It is recognized that $A_{i}$ will depend strongly on the unknown detailed stacking arrangement adopted by the surface of the deposited layer, which is in a continuous state of flux due to the dynamic deposition and reentrainment processes. However, within the assumptions of this paper, this stacking detail, or its variation, is unknown. The simple assumption, compatible with the assumption made in calculating $\phi_{e}$, is to take $A_{i}$ as proportional to the number and plan area of each aggregate, that is to assume, with $N_{d i}$ from Equation (A4), that

$$
A_{i} \propto d_{i}^{2} N_{d i} \propto d_{i}^{2}\left(\frac{v_{i}}{d_{i}^{3}}\right) \propto \frac{v_{i}}{d_{i}} .
$$

A further assumption is now needed to model the fractional area $C$ of unsubmerged aggregates associated with $i=j+1$ to $I$ (Figures A1a,b). This assumption needs to be consistent with assumptions made in calculating $\phi_{e}$, which are expressed in Fig. A1, namely, that smaller particles are more likely to be submerged than larger ones. Thus the assumption is made that 

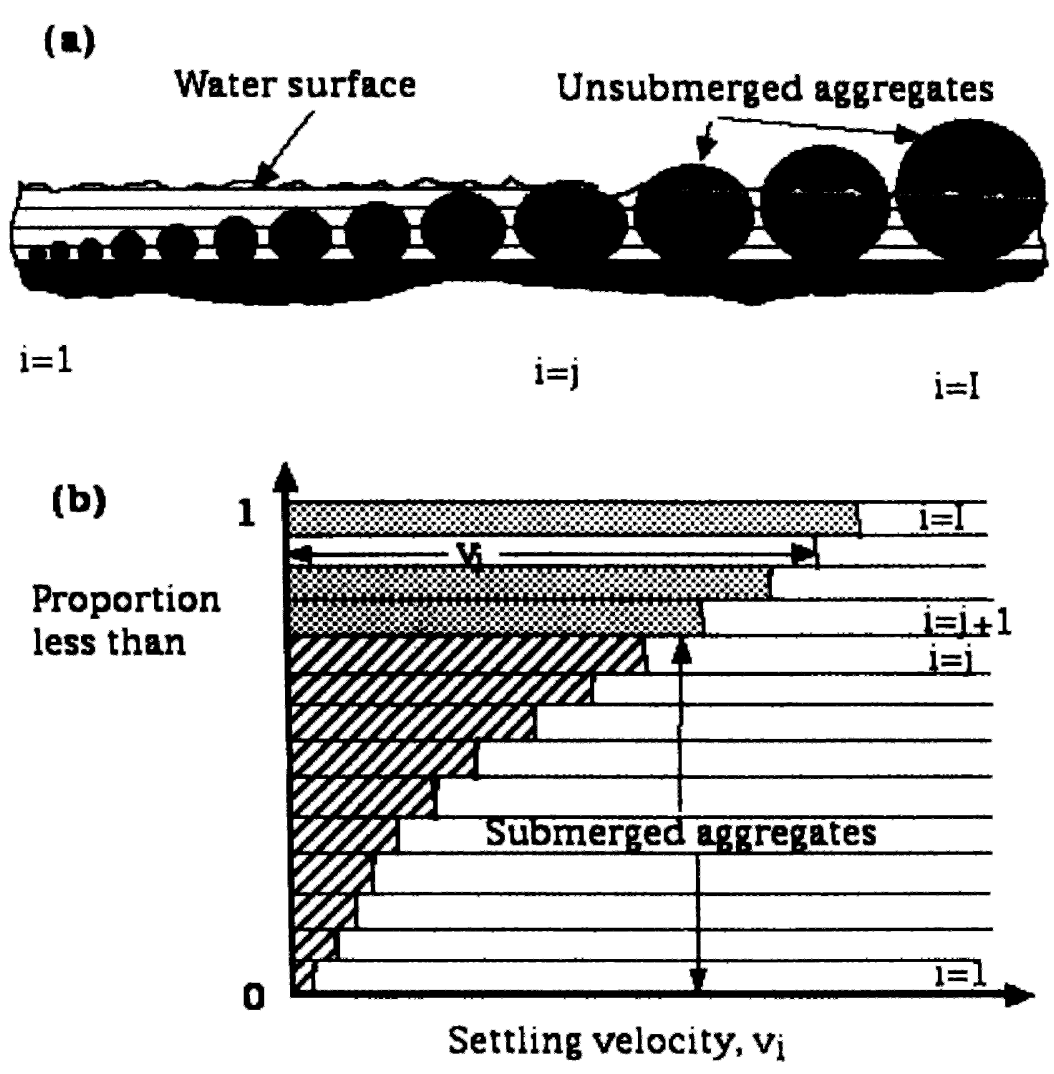

Figure A1. The decrease from depositability $(\phi)$ at full submergence to an effective depositability $\left(\phi_{e}\right)$ at part submergence of soil aggregates: (a) aggregates $i=1$ to $j$ submerged out of a total of $I$ classes; (b) schematic representation of settling velocity distribution for I soil classes, $j$ of which are submerged. Here $\phi$ is the mean settling velocity of $I$ classes, $\left(\phi_{e}\right)$ the mean settling velocity of the submerged classes (shown hatched).

$$
C=\sum_{i=j+1}^{i=I} A_{i} / \sum_{i=1}^{I} A_{i}
$$

or

$$
C=\sum_{i=j+1}^{i=I}\left(\frac{v_{i}}{d_{i}}\right) / \sum_{i=1}^{I}\left(\frac{v_{i}}{d_{i}}\right)
$$

so that

$$
(1-C)=\sum_{i=1}^{i=j}\left(\frac{v_{i}}{d_{i}}\right) / \sum_{i=1}^{I}\left(\frac{v_{i}}{d_{i}}\right),
$$

where $(1-C)$ will be called the "submerged fraction," indicating the fraction of surface immersed and subject to erosion. 
Earth Interactions - Volume 9 (2005) - Paper No. 5 • Page 22

Determining the soil's settling-velocity characteristic is required to calculate $\phi$ (or $\phi_{e}$ ). The Griffith University Depositability Program (GUDPRO), described in Lisle et al. (Lisle et al. 1996), allows $d_{i}$ to be approximately estimated from measured $v_{i}$, or alternatively, $v_{i}$ to be estimated from data on $d_{i}$ obtained, for example, by wet sieving. Thus the calculation of $(1-C)$ from Equation (A7) does not require any experimental information additional to that required to calculate $\phi$. In completely submerged flow, $C=0$ by definition, and so the term $(1-C)$ is unity.

Without introducing something like the mathematical model given by Equation (A7) into the numerator of Equation (1), the necessary reduction in $\phi$ to $\phi_{e}$ leads to ridiculous values of $c_{t}$ (Rose et al. 1997).

The implication of the partial submergence model of Equation (A7) is that whenever the soil surface is incompletely inundated by flow, the excess stream power $\left(\Omega-\Omega_{0}\right)$ in the theory for $c_{t}$ (Hairsine and Rose 1992a; Hairsine and Rose $1992 \mathrm{~b})$, should be multiplied by the submerged fraction $(1-C)$ in order to correctly estimate $c_{t}$.

\section{Theory development for high sediment concentrations}

\section{The enhanced density effect}

As explained in section 3.2, the density of water $\rho$ needs to be replaced by an effective density $\rho_{e}$, which recognizes the contribution of sediment to fluid density when sediment concentration is high. An expression for $\rho_{e}$ is now derived.

Consider the unit volume of a fluid whose sediment concentration (i.e., mass per unit volume of fluid) is $c$. Denote sediment dry density by $\rho_{s}$, and by $v_{s}$, the fractional volume occupied by sediment in unit volume of fluid. Then

$$
c=\rho_{s} v_{s}
$$

or

$$
v_{s}=c / \rho_{s}
$$

Then the mass of water in the unit volume is $\rho\left(1-v_{s}\right)$. Hence the effective density of sediment-laden water, $\rho_{e}$, is given by

$$
\begin{aligned}
\rho_{e} & =\text { total mass of water and sediment in unit volume } \\
& =\rho\left(1-c / \rho_{s}\right)+c .
\end{aligned}
$$

Hence

$$
\begin{aligned}
\rho_{e} & =\rho+\left(\frac{\rho_{s}-\rho}{\rho_{s}}\right) c \\
& =\rho+\eta c
\end{aligned}
$$

where $\eta=\left(\rho_{s}-\rho\right) / \rho_{s} \approx 0.62$ when $\rho_{s}$ is $\approx 2600 \mathrm{~kg} \mathrm{~m}^{-3}$.

If $c=450 \mathrm{~kg} \mathrm{~m}^{-3}$ (within the range reported in Table 1), then sediment contributes some $22 \%$ to the effective density. 


\section{Appendix B}

\section{Theory for Saltation Stress}

Removal of aggregates from the soil surface by eddy shear stresses or rainfall detachment will be assumed to be effectively vertical (Figure B1). In developing his model of sediment transport rate, Yalin (Yalin 1977) makes very similar assumptions to those expressed in Figure B1 concerning the trajectory of a particle that is assumed to be ejected vertically by an uplift force, the motion then becoming modified by interaction with the flowing water.

Consider a sedimentary particle of volume $\epsilon_{i}$ and mass $m_{i}$, where (in a complex particle or aggregate) some of the mass and volume could come from adsorbed and interstitial water. Denote the (wet) density of the particle by $\sigma$. In its saltating movement, assume that the particle or aggregate achieves the mean velocity of the flow, $V$, in the flow direction (likely to be an overestimate). Then the momentum gain by the particle is $m_{i} V$.

The particle under consideration has displaced a volume of fluid of mass $m_{w}=$ $\rho \varepsilon_{i}$, where $\rho$ is the density of water. The displaced volume of fluid would have had a momentum, $m_{w} V$, provided by the flow, had it not been displaced by the particle. Thus the extra momentum extracted from the flow due to the saltating particles is $\left(m_{i} V-m_{w} V\right)$. It is this momentum extraction that generates the saltation stress,
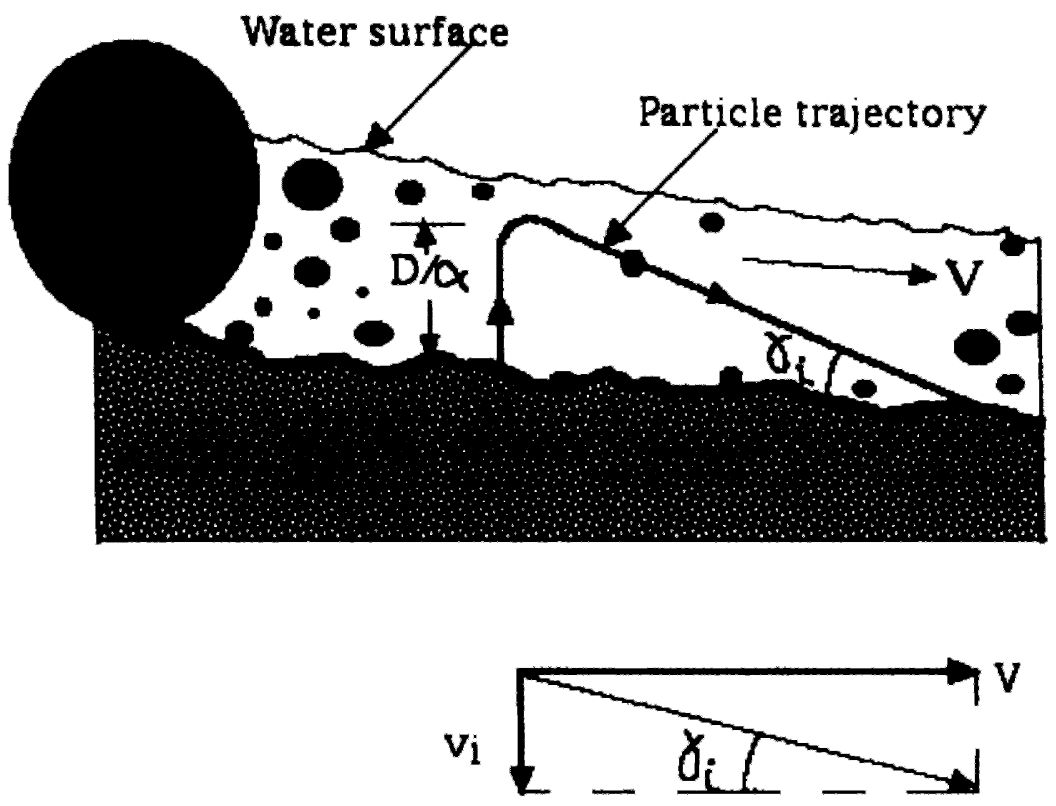

Figure B1. Idealization of the trajectory of a saltating aggregate, raised from the bed by turbulent Reynold's stresses, perhaps assisted by raindrop impact, and returning to the deposited layer in a distance $L_{i}$ governed by the average flow velocity $V$ and settling velocity $v_{i}$. 
Earth Interactions - Volume 9 (2005) - Paper No. 5 • Page 24

denoted by $\tau_{\mathrm{sa}}$. Furthermore, this extra momentum is gained over the trajectory distance $L_{i}$, so that the momentum expended by the fluid on the saltating particle per unit length of motion becomes

$$
\left(m_{i}-m_{w}\right) V / L_{i}
$$

where $m_{i}=\sigma \varepsilon_{i}$, and $m_{w}=\rho \varepsilon_{i}$.

The sediment concentration $\left(c_{i}\right)$ of particles in the size or settling-velocity class $i$ will be given by

$$
c_{i}=n_{i} m_{i}=n_{i} \sigma \varepsilon_{i}
$$

where $n_{i}$ is the number of particles per unit volume of fluid. The flux of saltating particles per unit width of flow in the size class $i\left(q_{s i}\right)$ is then given by definition as

$$
q_{s i}=q c_{i},
$$

where $q$ is the volumetric flux of water per unit width of flow. For flow of water of depth $D$,

$$
q=D V
$$

Equation (B1) will now be generalized, replacing $m_{i}$ by the saltation flux of particles of size class $i, q c_{i}$, and similarly replacing $m_{w}$ by $q n_{i} \rho \varepsilon_{i}$ [cf. Equation (B2)]. Thus the component of the saltation stress, $\tau_{\mathrm{sa}}$, which is contributed by particles in size class $i, \tau_{\mathrm{sa}}(i)$, is

$$
\tau_{\mathrm{sa}}(i)=q\left(n_{i} \sigma \varepsilon_{i}-n_{i} \rho \varepsilon_{i}\right) V / L_{i}
$$

or, from Equation (B4),

$$
\tau_{\mathrm{sa}}(i)=D V^{2} n_{i} \varepsilon_{i}(\sigma-\rho) / L_{i} .
$$

Suppose such potentially erodible sediment in the original soil matrix is divided into an arbitrary number $I$ settling velocity classes, each of equal mass. As recognized in Appendix B and Figure A1, the depth of overland flow may be inadequate to submerge sediment of all $I$ classes, with only $j$ such classes submerged. Assume the larger unsubmerged classes $j+1$ to $I$ remain stationary (even though they could roll). Water then flows between the larger sedimentary particles, much as (at a larger scale) water may flow between nonsubmerged rocks in a shallow stream.

If $c$ is the total sediment concentration of such flow, then since each class is of equal mass, $c_{i}=c / j$. The saltation stress $\tau_{\mathrm{sa}}$ is obtained by summing Equation (B5) over the settling velocity classes participating in saltation. Using Equation (B2) and summing Equation (B5) over the effective size classes $i=1$ to $j$ gives

$$
\tau_{\mathrm{sa}}=\left(\frac{\sigma-\rho}{\sigma}\right) D V^{2} \frac{c}{j} \sum_{i=1}^{j}\left(1 / L_{i}\right) .
$$


From the geometry of the saltation trajectory for a class $i$ particle shown in Figure B1, which defines the angle $\gamma_{i}$, it follows that, approximately,

$$
\tan \gamma_{i}=D /\left(L_{i} \alpha\right)
$$

where $\alpha$ is a factor $(\geq 1)$ which recognizes that a saltating particle may not rise to the full depth of flow (Croley 1982). Also, denoting the settling velocity of particles in class $i$ by $v_{i}$, it follows from Figure B1 that

$$
\tan \gamma_{i}=v_{i} / V \text {. }
$$

Thus, from Equations (B6) and (B7),

$$
L_{i}=\frac{D V}{v_{i} \alpha} .
$$

Substituting for $L_{i}$ from Equation (B9) into (B6),

$$
\tau_{\mathrm{sa}}=\left(\frac{\sigma-\rho}{\sigma}\right) \frac{c}{j} V \sum_{i=1}^{j} \alpha v_{i} .
$$

If, as an approximation, it is assumed that $\alpha=1$, which is reasonable in shallow flows well stirred by rainfall impact and other sources of turbulence, then from Equation (B10),

$$
\tau_{\mathrm{sa}}=\left(\frac{\sigma-\rho}{\sigma}\right) c V \sum_{i=1}^{j} v_{i} / j
$$

or

$$
\tau_{\mathrm{sa}}=\left(\frac{\sigma-\rho}{\sigma}\right) c V \phi_{e}
$$

where $\phi_{e}$ is the effective depositability considered earlier and in Rose et al. (Rose et al. 1997), which is given by

$$
\phi_{e}=\sum_{i=1}^{j} v_{i} / j .
$$

The surface shear stress $\left(\tau_{s}\right)$ effective in the entrainment of sediment or the reentrainment of deposited sediment is given by the difference between the total shear stress $(\tau)$ and the saltation stress $\left(\tau_{\mathrm{sa}}\right)$, so that

$$
\tau_{s}=\tau-\tau_{\mathrm{sa}}
$$

where, assuming nonaccelerating flow (a good assumption in overland flow with no sudden changes in slope or elevation of the land surface), hydraulic texts (e.g., Robertson et al. 1988) show that

$$
\tau=\rho_{e} g R_{h} S
$$

where $R_{h}$ is the hydraulic radius of flow if channelized, with $R_{h}=D$ for sheet flow, $g$ is the acceleration due to gravity, $S$ is the land slope, and $\rho_{e}$ is the effective density of the sediment-laden water. 
From Equations (B11), (B13), and (B14)

$$
\tau_{s}=\rho_{e} g R_{h} S-\left(\frac{\sigma-\rho}{\sigma}\right) c V \phi_{e},
$$

where $V$ can be calculated using Manning's equation [Equation (2)]. In the presence of rills, there is no analytical relation between water depth, flow velocity, and discharge. Then $D$ and $V$ were obtained using the Newton-Raphson numerical solution method as described in Yu and Rose (Yu and Rose 1997). Since $\tau_{s}$ is the effective shear stress for entrainment of sediment [Equation (B13)], the stream power, $\Omega$, in the theory of Hairsine and Rose (Hairsine and Rose 1992a; Hairsine and Rose 1992 b) must be replaced by an effective stream power, $\Omega_{s}$, given by

$$
\Omega_{s}=\tau_{s} V
$$

with $\tau_{s}$ given by Equation (B15).

Implications of the above saltation and surface stress theory for the general theory of reentrainment of deposited sediment at the transport limit, are considered in the main text.

\section{Appendix C}

\begin{tabular}{|c|c|c|}
\hline Symbol & Description & Defining equation/figure \\
\hline$A_{i}$ & Fraction of the soil surface occupied by size class $i$ sediment & Equation (A5) \\
\hline$b$ & A rill shape factor (fraction) & \\
\hline$c$ & Total sediment concentration, with bar denotes average $\left(\mathrm{kg} \mathrm{m}^{-3}\right)$ & \\
\hline$c_{i}$ & Sediment concentration of size class $i$ particles $\left(\mathrm{kg} \mathrm{m}^{-3}\right)$ & \\
\hline$c_{t}$ & $\begin{array}{l}\text { Total sediment concentration at the transport limit, with bar denotes } \\
\text { average }\left(\mathrm{kg} \mathrm{m}^{-3}\right)\end{array}$ & Equations (7) and (B2) \\
\hline & A component of $c_{t}$ & Equation (8) \\
\hline$c_{t}(\mathrm{HR})$ & $\begin{array}{l}c_{t} \text { calculated using theory of Hairsine and Rose (Hairsine and Rose } \\
\text { 1992a; Hairsine and Rose 1992b) }\end{array}$ & \\
\hline$C$ & $\begin{array}{l}\text { Fraction of the soil surface occupied by nonsubmerged sediment } \\
\text { (greater than size class } j \text { ), assumed not to erode }\end{array}$ & Equation (A6) \\
\hline$d_{i}$ & Effective diameter of particles in size class $i(\mathrm{~m})$ & \\
\hline$d_{50}$ & Median particle size $(\mathrm{m})$ & \\
\hline$D$ & Depth of water flow (m) & \\
\hline$F$ & $\begin{array}{l}\text { Fraction of the total stream power effective in entrainment and } \\
\text { reentrainment erosion (taken }=0.1 \text { ) }\end{array}$ & \\
\hline$g$ & Acceleration due to gravity $\left(\mathrm{m} \mathrm{s}^{-2}\right)$ & \\
\hline$i$ & A counter for size or settling velocity classes & Figure A1 \\
\hline$I$ & Arbitrary total number of size or settling velocity classes & Figure A1 \\
\hline$j$ & Number of sedimentary size classes that are submerged & Figure A1 \\
\hline$K_{1}$ & A term associated with saltation stress, dimensionless & Equation (5) \\
\hline$K_{2}$ & $\begin{array}{l}\text { A term associated with sediment enhancement of fluid density, } \\
\text { dimensionless }\end{array}$ & Equation (6) \\
\hline$K$ & Equal to $\left(1+K_{1}-K_{2}\right)$ & Equation (9) \\
\hline$L_{i}$ & Length of saltation trajectory of particle size class $i(\mathrm{~m})$ & Equation (B9) \\
\hline$m_{i}$ & Mass of a sedimentary particle in size class $i(\mathrm{~kg})$ & \\
\hline$m_{w}$ & Mass of water displaced by sedimentary particle of size class i $(\mathrm{kg})$ & \\
\hline
\end{tabular}

\section{List of Symbols}


Earth Interactions • Volume 9 (2005) • Paper No. 5 • Page 27

\begin{tabular}{|c|c|c|}
\hline Symbol & Description & Defining equation/figure \\
\hline$m$ & An exponent taken as $5 / 3$ & \\
\hline$M_{d i}$ & $\begin{array}{l}\text { Mass per unit area of sediment in the deposited layer of size class } i \\
\left(\mathrm{~kg} \mathrm{~m}^{-2}\right)\end{array}$ & $\begin{array}{l}\text { Equations (A1) and } \\
\quad(\mathrm{A} 2)\end{array}$ \\
\hline$M_{d t}$ & Total mass per unit area of sediment in the deposited layer $\left(\mathrm{kg} \mathrm{m}^{-2}\right)$ & Equation (A1) \\
\hline$n$ & Manning's roughness coefficient $\left[\mathrm{m}^{-(1 / 3)} \mathrm{s}\right]$ & Equations (2) and (3) \\
\hline$n_{i}$ & Number of particles per unit volume of fluid in size class $i$ & \\
\hline$N_{d i}$ & $\begin{array}{l}\text { Number of particles per unit area of size class } i \text { in the deposited } \\
\text { layer }\left(\mathrm{m}^{-2}\right)\end{array}$ & Equation (A3) \\
\hline$P_{t}$ & Total rainfall amount $(\mathrm{mm})$ & \\
\hline$P_{m}$ & Mean rainfall rate $\left(\mathrm{mm} \mathrm{h}^{-1}\right)$ & \\
\hline$P_{p}$ & Peak rainfall rate $\left(\mathrm{mm} \mathrm{h}^{-1}\right)$ & \\
\hline$q$ & $\begin{array}{l}\text { Volumetric flux per unit width of flow or unit flow rate }\left(\mathrm{m}^{3} \mathrm{~m} \mathrm{~s}^{-2}\right. \\
\left.\text { or } \mathrm{m}^{2} \mathrm{~s}^{-1}\right)\end{array}$ & Equation (B4) \\
\hline$q_{s i}$ & $\begin{array}{l}\text { Mass flux of saltating particles in size class } i \text { per unit land width } \\
\left(\mathrm{kg} \mathrm{m} \mathrm{s}^{-2}\right)\end{array}$ & Equation (B3) \\
\hline$Q$ & Runoff rate per unit area $\left(\mathrm{m} \mathrm{s}^{-1}\right)$ & \\
\hline$Q_{t}$ & Total runoff amount $(\mathrm{m})$ & \\
\hline$Q_{e}$ & Effective runoff rate $\left(\mathrm{m} \mathrm{s}^{-1}\right)$ & Equation (1) \\
\hline$R_{h}$ & Hydraulic radius in channelized flow (m) & \\
\hline$S$ & Land slope, the sine of the angle of incidence & \\
\hline$t$ & Time (s) & \\
\hline$v_{i}$ & Settling velocity of particles in size class $i\left(\mathrm{~m} \mathrm{~s}^{-1}\right)$ & Figures 1 and A1 \\
\hline$V$ & Mean velocity of water in overland flow $\left(\mathrm{m} \mathrm{s}^{-1}\right)$ & Equation (2) \\
\hline \multicolumn{3}{|l|}{ Greek } \\
\hline$\alpha$ & $\begin{array}{l}\text { A factor, } \geq 1 \text {, describing the fractional rise of a sedimentary particle } \\
\text { relative to water depth }\end{array}$ & Figure B1 \\
\hline$\beta$ & Soil erodibility parameter & Equation (10) \\
\hline$\gamma_{i}$ & Angle of saltation trajectory to the land surface $\left(^{\circ}\right)$ & $\begin{array}{l}\text { Figure B1/Equation } \\
\text { (B7) }\end{array}$ \\
\hline$\varepsilon_{i}$ & Volume of sedimentary particle in size class $i\left(\mathrm{~m}^{3}\right)$ & \\
\hline$\eta$ & $\left(\rho_{s}-\rho\right) / \rho_{s}$ & \\
\hline$\dot{\kappa}$ & Lag time & \\
\hline$\rho$ & Density of water $\left(1000 \mathrm{~kg} \mathrm{~m}^{-3}\right)$ & \\
\hline$\rho_{e}$ & Effective density of sediment-laden water $\left(\mathrm{kg} \mathrm{m}^{-3}\right)$ & Equations (4) and (A8) \\
\hline$\rho_{s}$ & Dry density of sediment $\left(\mathrm{kg} \mathrm{m}^{-3}\right)$ & \\
\hline$\sigma$ & Wet density of particle or aggregate $\left(\mathrm{kg} \mathrm{m}^{-3}\right)$ & \\
\hline$\Sigma$ & Summation sign & \\
\hline $\bar{\tau}$ & Total shear stress between soil and overland flow $\left(\mathrm{N} \mathrm{m}^{-2}\right.$ or $\left.\mathrm{Pa}\right)$ & Equation (B14) \\
\hline$\tau_{s}$ & $\begin{array}{l}\text { Surface shear stress effective in entrainment and reentrainment } \\
\left(\mathrm{N} \mathrm{m}^{-2} \text { or } \mathrm{Pa}\right)\end{array}$ & $\begin{array}{l}\text { Equations (B13) and } \\
\text { (B15) }\end{array}$ \\
\hline$\tau_{\mathrm{sa}}$ & Saltation stress $\left(\mathrm{N} \mathrm{m}^{-2}\right.$ or $\left.\mathrm{Pa}\right)$ & $\begin{array}{l}\text { Equations (B5) and } \\
\quad(\mathrm{B} 11)\end{array}$ \\
\hline$\phi$ & Depositability of the sediment $\left(\mathrm{m} \mathrm{s}^{-1}\right)$ & \\
\hline$\phi_{e}$ & Effective depositability of the sediment $\left(\mathrm{m} \mathrm{s}^{-1}\right)$ & Equation (B12) \\
\hline$\Omega$ & $\begin{array}{l}\text { Total stream power, fraction } F \text { of which is effective in erosion } \\
\left(\mathrm{W} \mathrm{m}^{-2}\right)\end{array}$ & \\
\hline$\Omega_{0}$ & Threshold value of $\Omega$ below which no erosion occurs ( $\mathrm{W} \mathrm{m}^{-2}$ ) & \\
\hline$\Omega_{\mathrm{s}}$ & Modified stream power $\left(=\tau_{s} V\right)$ & Equation (B16) \\
\hline
\end{tabular}

\section{References}

Abrahams, A. D., A. J. Parsons, and S.-H. Luk, 1989: Distribution of depth of overland flow on desert hillslopes and its implications for modelling soil erosion. J. Hydrol., 106, 177-184. 
Bagnold, R. A., 1941: The Physics of Blown Sand and Desert Dunes. Chapman and Hall, London, $265 \mathrm{pp}$.

Bonell, M., and J. Williams, 1987: Infiltration and description of overland flow and sediment on a low relief landscape in semi-arid tropical Queensland. Forest Hydrology and Watershed Management, R. H. Swanson, P. Y. Bernier, and P. D. Woodward, Eds., IAHS Publication No. 167, 199-211.

Ciesiolka, C. A. A., and C. W. Rose, 1998: The measurement of soil erosion. Soil Erosion at Multiple Scales-Principles and Methods for Assessing Causes and Impacts, F. W. T. Penning de Vries, F. Agus, and J. Kerr, Eds., CABI Publishing, 287-301.

—, K. J. Coughlan, C. W. Rose, M. C. Escalante, G. M. Hashim, E. P. Paningbatan, and S. Sombatpanit, 1995: Methodology for a multi-country study of soil erosion management. Soil Technol., 8, 179-192.

Coughlan, K. J., and C. W. Rose, Eds., 1997: A new soil conservation methodology and application to cropping systems in tropical steeplands. ACIAR Tech. Rep. 40, ACIAR, Canberra, Australia, $147 \mathrm{pp}$.

Croley, T. E., II, 1982: Unsteady overload flow sedimentation. J. Hydrol., 56, 325-346.

Dangler, E. W., and S. A. El-Swaify, 1976: Erosion of selected Hawaii soils by simulated rainfall. Soil Sci. Soc. Amer. J., 40, 769-773.

Engman, E. T., 1986: Roughness coefficients for routing surface runoff. J. Irrig. Drain. Eng., 112, 39-53.

FAO, 1988: Watershed management and field manual-Slope treatment measures and practices. Conservation Guide 13/3, Rome, Italy, 144 pp.

Fentie, K. J., K. J. Coughlan, and C. W. Rose, 1999: Manual for use of program GUEST 3.0. ENS Working Paper 1/99, Faculty of Environmental Sciences, Griffith University, Brisbane, Australia, $37 \mathrm{pp}$.

Hairsine, P. B., and C. W. Rose, 1991: Rainfall detachment and deposition: Sediment transport in the absence of flow-driven processes. Soil Sci. Soc. Amer. J., 55, 320-324.

$\longrightarrow$, and _ 1992a: Modeling water erosion due to overland flow using physical principles. I. Sheet flow. Water Resour. Res., 28, 237-243.

— Rill flow. Water Resour. Res., 28, 245-250.

Lal, R., 1990: Soil Erosion in the Tropics: Principles and Management. McGraw-Hill, 580 pp.

Lawrence, D. S., 1997: Macroscale surface roughness and frictional resistance in overland flow. Earth Surface Processes Landforms, 22, 365-382.

Liao, M. C., and W. L. Wu, 1987: Soil conservation on steeplands in Taiwan. Chinese Soil and Water Conservation Society, Taipei, Taiwan, 112 pp.

Lisle, I. G., K. J. Coughlan, and C. W. Rose, 1996: GUDPRO 3.1: A program for calculating particle size and settling velocity characteristics. User guide and reference manual, ENS Working Paper 7/96, Faculty of Environmental Sciences, Griffith University, Brisbane, Australia, $29 \mathrm{pp}$.

Lovell, C. J., and C. W. Rose, 1988: Measurement of soil aggregate settling velocities. I. A modified bottom withdrawal tube. Aust. J. Soil Res., 26, 55-71.

Morgan, R. P. C., and Coauthors, 1988: The European soil erosion model (EUROSEM): A dynamic approach for predicting sediment transport from fields and small catchments. Earth Surface Processes Landforms, 23, 527-544.

Nearing, M. A., G. R. Foster, L. J. Lane, and S. C. Finkner, 1989: A process based erosion model for USDA water erosion prediction project technology. Trans. Amer. Soc. Agric. Eng., 32, 1587-1593.

Pal, D., S. N. Prasad, and M. Römkens, 2000: Optimal mode of sediment transport by shallow flows in upland areas. Int. J. Sediment Res., 15 (2), 260-267. 
Paningbatan, E. P., C. A. A. Ciesiolka, K. J. Coughlan, and C. W. Rose, 1995: Alley cropping for managing soil erosion of hilly lands in the Philippines. Soil Technol., 8, 193-204.

PCARRD, 1992: Management and rehabilitation of degraded hillylands-Terminal report of the PCARRD/IBSRAM project, Report, PCARRD, Los Baños, Laguna, Philippines, 220 pp.

Presbitero, A. L., 2003: Soil erosion studies on steep slopes of humid-tropic Philippines. Ph.D. thesis, Griffith University, Nathan Campus, Queensland, Australia, 644 pp.

— , M. C. Escalante, C. W. Rose, K. J. Coughlan, and C. A. A. Ciesiolka, 1995: Erodibility evaluation and the effect of land management practices on soil erosion from steep slopes in Leyte, the Philippines. Soil Technol., 8, 205-213.

Robertson, J. A., J. J. Cassidy, and M. H. Chaudhry, 1988: Hydraulic Engineering. Houghton Mifflin Co., 662 pp.

Roose, E. J., 1977: Application of the Universal Soil Loss Equation of Wischmeier and Smith in West Africa. Conservation and Soil Management in the Humid Tropics, D. J. Greenland and R. Lal, Eds., Wiley, 177-187.

Rose, C. W., 1993: Erosion and sedimentation. Hydrology and Water Management in the Humid Tropics-Hydrological Research Issues and Strategies for Water Management, M. Bonell et al., Eds., Cambridge University Press, 301-343.

—_ 1995: Special Issue: Soil Erosion and Conservation. Soil Technol., 8 (3), 258 pp.

_ 1998: Modeling erosion by water and wind. Methods for Assessment of Soil Degradation, R. Lal et al., Eds., CRC Press, 57-88.

— , W. L. Hogarth, G. C. Sander, I. Lisle, P. B. Hairsine, and J.-Y. Parlange, 1994: Modelling processes of soil erosion by water. Trends Hydrol., 1, 443-452.

— K. K. Coughlan, C. A. A. Ciesiolka, and B. Fentie, 1997: Program GUEST (Griffith University Erosion System Template). A New Soil Conservation Methodology and Application to Cropping Systems in Tropical Steeplands, K. J. Coughlan and C. W. Rose, Eds., ACIAR Tech. Rep. 40, ACIAR, 34-58.

Ross, S., 1989: Soil Processes: A Systematic Approach. Routledge, Chapman and Hall, 444 pp.

Rouhipour, H., 1997: Interaction between flow-driven and rainfall-driven soil erosion processes. Ph.D. thesis, Griffith University, Nathan Campus, Queensland, Australia, 296 pp.

World Bank, 1989: Philippine environment and natural resource management study-A World Bank country study. The World Bank, Washington, DC, 170 pp.

Wischmeier, W. H., and D. D. Smith, 1978: Predicting rainfall erosion losses-A guide to conservation planning. Agricultural Handbook No. 537, U.S. Department of Agriculture, Washington, DC, $58 \mathrm{pp}$.

Yalin, M. S., 1977: Mechanics of Sediment Transport. 2d ed. Pergamon Press, 219 pp.

Yu, B., and C. W. Rose, 1997: GUEPS 1.2 A program for calculating the soil erodibility parameter $\beta$ and predicting the amount of soil loss using GUEST methodology. User guide and reference manual, ENS Working Paper 3/97, Faculty of Environmental Sciences, Griffith University, Nathan Campus, Brisbane, Queensland, Australia, 25 pp.

— , and — 1999: Application of a physically based soil erosion model, GUEST, in the absence of data on runoff rates. I. Theory and methodology. Aust. J. Soil Res., 37, 1-11.

,-- K. J. Coughlan, and B. Fentie, 1997a: Plot-scale rainfall-runoff characteristics and modeling at six sites in Australia and Southeast Asia. Trans. Amer. Soc. Agric. Eng., 40, 1295-1303.

$\longrightarrow,-$ C. A. A. Ciesiolka, K. J. Coughlan, and B. Fentie, 1997b: Towards a framework for runoff and soil loss prediction using GUEST technology. Aust. J. Soil Res., 35, 1191-1212.

— - A. Sajjapongse, D. Yin, Z. Eusof, C. Anecksamphant, C. W. Rose, and U. Cakurs, 1999: Application of a physically based soil erosion model, GUEST, in the absence of data on 
Earth Interactions - Volume 9 (2005) • Paper No. 5 • Page 30

runoff rates. II. Four case studies from China, Malaysia, and Thailand. Aust. J. Soil Res., 37, $13-31$.

C. W. Rose, C. A. A. Ciesiolka, and U. Cakurs, 2000: The relationship between runoff rate and lag time and the effect of surface treatments at the plot scale. Hydrol. Sci. J., 45, 709-726.

Earth Interactions is published jointly by the American Meteorological Society, the American Geophysical Union, and the Association of American Geographers. Permission to use figures, tables, and brief excerpts from this journal in scientific and educational works is hereby granted provided that the source is acknowledged. Any use of material in this journal that is determined to be "fair use" under Section 107 or that satisfies the conditions specified in Section 108 of the U.S. Copyright Law (17 USC, as revised by P.IL. 94-553) does not require the publishers' permission. For permission for any other form of copying, contact one of the copublishing societies. 